\title{
Measurement of particle size distribution and specific surface area for crushed concrete aggregate fines
}

Rolands Cepuritis ${ }^{\text {a,b,* }}$, tel.: +47 95133075, rolands.cepuritis@norcem.no

Edward J. Garboczi ${ }^{\mathrm{c}}$, edward.garboczi@nist.gov

Chiara F. Ferraris ${ }^{\mathrm{d}}$, chiara.ferraris@nist.gov

Stefan Jacobsen ${ }^{\text {a }}$, stefan.jacobsen@ntnu.no

Bjørn Eske Sørensen ${ }^{\mathrm{e}}$, bjorn.sorensen@ntnu.no

${ }^{a}$ Department of Structural Engineering, Norwegian University of Science and Technology, NO7491 Trondheim, Norway

${ }^{\mathrm{b}}$ Norcem AS (HeidelbergCement), R\&D Department, Setreveien 2, Postboks 38, NO-3950 Brevik, Norway

${ }^{c}$ National Institute of Standards and Technology, Boulder, CO 80305, United States

${ }^{d}$ National Institute of Standards and Technology, Gaithersburg, MD 20899, United States

${ }^{\mathrm{e}}$ Department of Geology and Mineral Resources Engineering, Norwegian University of Science and Technology, Sem Sælands vei 1, NO-7491 Trondheim, Norway

Abstract: Different methods for measuring particle size distribution (PSD) and specific surface area of crushed aggregate fines $(\leq 250 \mu \mathrm{m})$, produced by high-speed vertical shaft impact (VSI) crushing of rock types from different quarries in Norway, have been investigated. Among all the methods studied, X-ray sedimentation is preferred because it has adequate resolution and requires fewer and more reliable input parameters. This combination makes it suitable for practical applications at hard rock quarries. X-ray microcomputed tomography $(\mu \mathrm{CT})$ combined with spherical harmonic analysis was applied to estimate the actual error introduced when PSD measurements were used to calculate the specific surface area of the VSI crushed rock fines. The $\mu \mathrm{CT}$ results, to the limit of their resolution, show that the error in the calculated surface area caused by assuming spherical particles (a common assumption in PSD measurements) is of unexpectedly similar magnitude (-20\% to $-30 \%)$ over the entire investigated particle size range, which was approximately $3 \mu \mathrm{m}$ to $200 \mu \mathrm{m}$. This finding is important, becauses it simplifies relative surface area determination and is thought to be quite general, since the crushed aggregate fines investigated were produced from 10 rock types that had a wide range of mineralogies. 


\section{Partial contribution of NIST - not subject to US copyright}

Keywords: Crushed aggregate fines; laser diffraction; sedimentation; dynamic image analysis; X-ray tomography

\section{INTRODUCTION}

The concrete aggregate industry has historically limited particle size distribution (PSD) analysis, for fine particles, to simply determining the mass fraction of particles passing a sieve with square openings of minimum edge length $0.063 \mathrm{~mm}$ (according to $\mathrm{EN} \mathrm{933-1} \mathrm{[1])} \mathrm{or} 0.075 \mathrm{~mm}$ (according to ASTM C136 [2]). The European industry standard method intended for analysing the grading of filler aggregates, namely EN 933-10 [3], is similar. This standard only describes a method of more precisely determining the amount of particles that are smaller than $0.063 \mathrm{~mm}$, but not differentiating the particles beyond that. On the other hand, natural and manufactured concrete fine aggregates (sand) have been reported to include particles down to the submicrometer size range [4], [5], [6], [7]. The importance of a more detailed fine particle analysis has become more evident during the last few decades, with the need to replace the use of depleting natural sand materials, which normally contain little of the fine material that passes a $0.063 \mathrm{~mm}$ sieve, with manufactured crushed sands that generally include a much higher fine material content [8]. Accurate determination of the particle size distribution (PSD) of this material in the size range $\leq 0.063 \mathrm{~mm}$ is expected to provide valuable information for concrete proportioning [4], [5], [9], [10], [11], [6]. Fines have a significant influence on most concrete properties, both in fresh and in hardened concrete. The PSD and specific surface area are the main parameters used to describe fines. Furthermore, the influence of fines is even more pronounced for modern high-workability concrete such as self-compacting concretes [11], [6], [7].

As there is no standard procedure covering the whole range of concrete aggregate PSD, different researchers [12], [4], [13], [10], [14] , [5], [11], [6], [7] have used widely different measurement methods. It is, however, well-established from research within the geological sciences on 
analysing natural sediments of similar grain size distributions [15], [16], [17], [18] that different measurement methods can yield very different results depending on the properties of the analysed materials. A recent study [7] suggested that this can also be true for crushed concrete aggregate filler materials. Therefore, a variety of measurement techniques has been investigated in this paper to better understand how the size and surface area of fine particles can be determined and how the results can be interpreted in terms of particle size, surface area, and shape.

\section{MATERIALS AND METHODS}

\subsection{Materials}

Fine aggregate powder (filler) materials used for the study were produced from 10 different blasted and crushed rocks with an original size range of about $4 \mathrm{~mm}$ to $22 \mathrm{~mm}$. Further processing included Vertical Shaft Impact (VSI) crushing to generate fines and air-classification into three distinct size fractions with approximately the following $d_{10}$ to $d_{90}$ ranges: $4 \mu \mathrm{m}$ to 25 $\mu \mathrm{m}, 20 \mu \mathrm{m}$ to $60 \mu \mathrm{m}$ and $40 \mu \mathrm{m}$ to $250 \mu \mathrm{m}$ (Table 1). The size parameter $\mathrm{d}_{\mathrm{N}}$ is the maximum diameter of the smallest $\mathrm{N} \%$ of the particles by mass. Thirty different fine powder samples were produced: three particle size ranges for each of the 10 rock types with different mineralogical compositions (

Table 2). The finest of powder fractions $(4 \mu \mathrm{m}$ to $25 \mu \mathrm{m}$ ) included all the particles smaller than 4 $\mu \mathrm{m}$ generated during the crushing and afterwards extracted by air-classification. Mineralogical composition of the powders was determined by quantitative X-ray diffraction (XRD) analysis. The samples were first ground using a micronizing mill with agate grinding elements to a fineness of $\mathrm{d}_{50}$ approximately equal to $10 \mu \mathrm{m}$, using ethanol as a grinding fluid, and subsequently dried overnight at $85{ }^{\circ} \mathrm{C}$ in a covered petri dish. After drying, the sample material was put in a poly(methyl methacrylate) (PMMA) specimen holder following minor adaptations of standard procedures [19]. XRD data were collected in a Bruker ${ }^{*}$ X-ray Diffractor D8 Advance, using

\footnotetext{
* Commercial equipment, instruments, and materials mentioned in this paper are identified in order to foster understanding. Such identification does not imply recommendation or endorsement by the National Institute of Standards and Technology (NIST), nor does it imply that the materials or equipment identified are necessarily the best available for the purpose.
} 
$40 \mathrm{kV}, 40 \mathrm{~mA}$ and $\mathrm{CuK} \alpha$ radiation of wavelength $\mathrm{K} \alpha 1=0.15406 \mathrm{~nm}$ and $\mathrm{K} \alpha 2=0.154439 \mathrm{~nm}$ and a $\mathrm{K} \alpha 1 / \mathrm{K} \alpha 2$ ratio of 0.5 . Diffractograms were recorded at diffraction angles $(2 \theta)$ from $3^{\circ} 2 \theta$ to $65^{\circ}$, in $0.009^{\circ}$ increments with $0.6 \mathrm{~s}$ counting time per increment. The total analysis time per sample was $71 \mathrm{~min}$. Further analysis was based on the X-ray powder diffraction results and the minerals in the ICDD database implemented in the software Bruker EVA®. The first step was mineral identification, and then the peaks of each mineral were scaled manually to give the best fit to the observed XRD diffractogram. The semi-quantitative mineralogy found based on $2 \theta$ intensity data analyzed by the XRD instrument was passed to the software Topas Rietveld XRD, which was used to perform a structural refinement. The results of the analysis ( Table 2) are provided only for the $4 \mu \mathrm{m}$ to $25 \mu \mathrm{m}$ fractions, but the mineralogical composition was in fact determined for all three size ranges of the fillers. The compositional variation among different particle sizes of the same rock type was relatively small, which is why all of the results have not been reported here. The uncertainty in the mineralogical compositions presented in Table 2 is estimated to be about $\pm 1.6 \%$ out of the mass- $\%$ for a single mineral phase at the $95 \%$ confidence level, as also demonstrated for rock material by Hestnes \& Sørensen [20]. The groups of minerals used in

Table 2 can include up to three different individual minerals.

Table 1: Crushed rock fines used for the study.

Table 2: Mineralogical composition of $4 \mu \mathrm{m}$ to $25 \mu \mathrm{m}$ powder fractions determined with quantitative XRD.

\subsection{Methods for PSD, specific surface and shape characterization}

Four different methods were used for measuring the PSD of the crushed fines. These were wetmethod laser diffraction (LD), X-ray sedimentation (XS), X-ray microcomputed tomography $(\mu \mathrm{CT})$ combined with spherical harmonic analysis, and dynamic image analysis (DIA). An approximate specific surface area can be calculated from the result of any of these PSD measurements. A fifth method, nitrogen $\left(\mathrm{N}_{2}\right)$ adsorption BET method analysis, was used only for direct specific surface area measurements. 
These measurement methods are well-known techniques that have been widely used for characterising other materials, so a detailed description of each method will not be given here. It is recommended, if details are desired, to refer to [15], [21], [22] for LD and XS methods, [23], [24], [25], [14], [26] for $\mu \mathrm{CT}$, [21], [26] for DIA and [27] for the BET method. In this paper, the results of these techniques applied to characterising crushed concrete aggregate fines will be discussed.

\subsubsection{Wet method laser diffraction}

All wet method LD measurements were performed using a Mastersizer 2000 (Malvern Instruments) Hydro 2000S wet sample dispersion unit with recirculating pump. A powder sample was added to a circulating isopropyl alcohol (IPA) previously loaded into the instrument, until the vendor recommended obscuration level [28] was obtained (between $10 \%$ and $20 \%$ ). The next step included dispersion by ultrasonic agitation, after which the average of six repeated measurements was used to characterize the PSD.

Accuracy of the same measurements have been evaluated by Hackley et al. [29] for cement powder $\left(\mathrm{d}_{50} \approx 10 \mu \mathrm{m}\right.$ and $95 \%$ by mass passing a $45 \mu \mathrm{m}$ sieve) dispersed in IPA when the results were analysed with the Mie optical model (see below). Three levels of precision were examined: run (the same sample analysed in replicate sequential runs), subsample (several subsamples prepared from a single powder sample) and sample (several samples taken for analysis from the same bulk material container) by determining the coefficient of variation (CV) for three characteristic diameters $\left(\mathrm{d}_{10}, \mathrm{~d}_{50}\right.$ and $\left.\mathrm{d}_{90}\right)$. It was found that the precision of replicate sequential runs within a single sample was very good, with coefficients of variation near $1 \%$. The subsample-to-subsample and sample-to-sample variations were similar to each other in magnitude, with CVs ranging from $5 \%$ for $\mathrm{d}_{10}$ up to $16 \%$ for $\mathrm{d}_{90}$. Hackley et al. [29] concluded that this seems to indicate that the most significant contribution to uncertainty in the measured PSDs arises during the process of diluting the sample prior to analysis or in the sampling process itself.

Transformation of the measured diffraction patterns to a PSD uses scattering theory and therefore requires knowledge of the particles' optical properties. Sources of uncertainty that are related to the tested material optical properties arise from the mathematical analysis of the 
measured diffraction spectrum. To understand the material properties affecting this, the relationship between light and particle surfaces has to be briefly introduced (Figure 1). Figure 1 shows the four possible types of interaction: diffraction, reflection, refraction, and absorption. Because the surface of a particle produces an electromagnetic field due to the presence of electrons and since light is an electromagnetic radiation, it can interact with the surface to produce a phenomenon that is described as diffraction [30]. In diffraction, at some distance from the particle in the direction of the incident light, a pattern will develop that is dependent solely upon the size of the particle and the wavelength of the incident light. From this pattern, information can be obtained which is related to the size of the particle [30].

Figure 1: Four types of interaction between light and surface.

Light can also be reflected from the surface of a particle or absorbed by the particle. The fourth kind of interaction is refraction. It can happen in particles that are somewhat transparent to the incident light. In this case, light can pass through the particle [30] but the direction of propagation is changed (bent).

As mentioned above, diffraction is solely dependent upon the size of the particle, which is why pure diffracted light is the desirable information that should be used for particle size measurements. Reflection has no effect on diffraction but it may affect refraction if the surface is sufficiently reflective. Refraction can have considerable impact on a diffraction pattern, but the magnitude of the effect is highly dependent upon the size and shape of the particle [30].

The key material property (other than size and shape) that will impact the analysis of the diffraction pattern results, under Mie theory, is the complex refractive index $m=n+\mathrm{i} k$ [29], which is a combination of the real refractive index component $(n)$ for a substance compared to a vacuum and the imaginary (absorptive) component (ik). The real refractive index component defines where the exiting refracted light will focus and spread, while the imaginary component is an indication of the intensity of the refracted light. If the imaginary component is low, the intensity of the refracted light will be high. 
Depending on the nature of the diffraction pattern, the appropriate optical model has to be chosen. For particles larger than about $25 \mu \mathrm{m}$, the choice is simple, because Frauenhofer diffraction theory can provide accurate analysis and does not require input of the optical constants (real and imaginary parts of the complex refractive indices) [29]. For opaque particles or those having large refractive index contrast with the medium, the range of validity of the Frauenhofer model is limited at the fine end to diameters a few times higher than the wavelength of the light $(\lambda)$ [31]. For transparent particles, or particles with moderate refraction contrast, the lower limit is raised to about $40 \lambda$, which is approximately $25 \mu \mathrm{m}$ for the visible wavelengths used in most LD equipment [31]. It is thus clear why for fine particles, and depending on the refractive index of the material, significant errors can occur, if only the Frauenhofer theory is applied. For these cases, the Mie scattering theory is used [29]. The use of the Mie model requires knowledge of the optical constants of the analysed particles and this is when difficulties in measuring the PSD of crushed aggregate fines can arise.

The real refractive indices for many common single-phase solids can be found in handbooks, such as [32] and [33]. However, for multiphase crushed aggregate fines ( Table 2), selection of appropriate refractive indices can be problematic. In fact, depending on the crystal structure of the minerals, the real refractive index can be different depending on the direction of the incident light with respect to the orientation of the crystal [32]. However, the assumption is made that a spherical average over all crystallographic directions is sufficient, since a powder presents all direction as equally likely. Typical practice for LD measurements on multi-phase materials is then using vendor-supplied approximate values based on only the rock name or determining some "mean" values based on the known optical constants for each constituent pure mineral phase. Nevertheless, such an approach is difficult in practice, because it would involve a need for quantitative determination of the mineral phases prior to LD measurements.

Table 3 summarizes the real component of the refractive index along each of the principal optical axes of each of the main mineral phases (

Table 2) included in the rocks from this study. The data indicate that the real component varies from 1.486 to 1.765 , depending on the type of mineral and direction of the incident light relative to the orientation of the mineral. However, nine out of ten rock types present in 
Table 2 are dominated by quartz, carbonate, feldspar and sheet silicate minerals, which in fact have similar values for the weighted averages of their refractive indices. This indicates that a value of about 1.55 can be used for most of the rock-types studied, even without rigorous analysis of the mineralogical composition. This simplification is more dubious for basalt, which comprises a considerable percentage of epidote minerals with the overall average real refractive index value 1.72. Thus a refractive index of about 1.60 would be recommended for the basalt aggregate, reflecting the average of all the minerals analysed.

Table 3: Real part of the complex refractive indices of the crushed aggregate fines used for the study [32], [34], [35].

The light absorption of the particles can become more important primarily for the very fine fraction of the crushed fillers (i.e. below about $1 \mu \mathrm{m}$ in size). However, the imaginary refractive component $(\mathrm{k})$, which describes this phenomenon in the Mie optical model, is much more difficult to determine and/or find in the published sources [36], [37] than the real refractive component (n). This often represents a significant challenge for applying light scattering methods for very fine particle sizes [37]. The usual approach is simply choosing a value from 0 to 1.0 depending on the powder appearance -0 for fully transparent particles and 1.0 for completely absorptive. In the case of powders, such as crushed aggregate fines, values of $\mathrm{k}=0.01$ are recommended for crystalline transparent powders, $\mathrm{k}=0.1$ for slightly coloured powders and 1.0 for highly coloured powders [38]. For example, for portland cement, which is typically grey to off-white in colour, a value of 0.1 is often reported [29, 39]. However, the appropriateness for general use of such a value has not been established [29]. Given that most of the crushed fines used for the study resembled portland cement in their appearance (colour), a value of $\mathrm{k}$ of 0.1 was chosen as the reference value for all of them. The uncertainty imposed by such an arbitrary choice is treated in the results section of this paper.

\subsubsection{X-ray sedimentation $(\mathrm{XS})$}

All the measurements were performed using a Micromeritics SediGraph 5100, a device that measures PSD based on particle sedimentation speed and equivalent Stokes diameter. All the vendor's recommended procedures were followed and a vendor-supplied particle dispersion liquid was used that had a specific gravity of $0.76 \mathrm{~g} / \mathrm{cm}^{3}$ and a viscosity of $1.0 \mathrm{mPa}$.s to 1.5 mPas. 
The XS equipment is designed to measure particles in the size range of about $0.1 \mu \mathrm{m}$ to $300 \mu \mathrm{m}$. However, due to the limited sample size for analysis (only about $2 \mathrm{~g}$ ) in the instrument, the usual practice for measurements is removing the coarsest particles above about $60 \mu \mathrm{m}$ in size by dry sieving, and then combining these results together with the sedimentation analysis of the finest particles [15], [40]. A smooth total PSD curve is obtained only after applying conversion factors [15], [40], due to the different principles of measurement for the fine and coarse particles. For the given study, $100 \mu \mathrm{m}$ was chosen as the particle size above which dry-sieving analysis was used.

Density is the only property that is normally used as an input parameter for XS analysis. The density of each sample was measured by helium pycnometry (Table 4). It must also be noted that the XS method is based on the assumption that classifying particles by their sedimentation velocity is equivalent to classifying them by size. This is true for spheres, but not true for arbitrary shapes, as shown experimentally [41], [42].

Table 4: Densities of the analyzed crushed aggregate fines as measured by helium pycnometry.

Oliver et al. [43] have estimated that the combined uncertainty from the mechanical and electrical components of a XS instrument is less than $\pm 1 \%$. By analysing different fractions of mud and silt, Coates and Hulse [40] also concluded that the precision of the instrument on the same sample analysed in replicate sequential runs was well within the $\pm 1 \%$ standard deviation of the cumulative percent value for each size subclass. A much higher degree of variation (up to a standard deviation of $\pm 4.37 \%$ ) was observed when several subsamples were obtained from the same sample. Coates and Hulse [40] concluded that this is caused by the sampling procedure of splitting the sample down to $2 \mathrm{~g}$.

Sources of uncertainty related to the tested material properties can arise from particle shape (spherical shape is assumed in the Stoke's law), Brownian motion of the particles in the size range below about $1 \mu \mathrm{m}$, X-ray absorption effects (minerals with $\mathrm{Mg}, \mathrm{Fe}$, and $\mathrm{Ti}$ have very high absorption coefficients), and a wide range of densities for the mineral components of a crushed aggregate sample [15], since only the average is typically used. 


\subsubsection{X-ray $\mu \mathrm{CT}$ combined with spherical harmonic analysis}

Combining X-ray $\mu \mathrm{CT}$ with spherical harmonic analysis for particle size and shape measurements is discussed in detail in [23], [24], [25], [14], [26] and has been applied to very similar crushed aggregate materials in [7]. Sample preparation involved casting samples of the crushed powders in epoxy at about $5 \%$ volume concentration and allowing hardening without segregation. After hardening, the samples were scanned using $\mu \mathrm{CT}$ equipment and complete three-dimensional renderings of the digitized particle size and shape were obtained within the limitation of the voxel size used. Particles down to the volume of $8 \times 8 \times 8=512$ voxels were used for compiling the resulting PSDs. This lower limit is employed since smaller particles are hard to distinguish from background noise in the $\mu \mathrm{CT}$-scanning, and not enough of details of the particle geometry can be obtained for an accurate spherical harmonic fit of these smaller particles. The $\mu \mathrm{CT}$ data presented here were collected by a benchtop scanner (Skyscan 1172 by Bruker), used for the $20 \mu \mathrm{m}$ to $60 \mu \mathrm{m}$ and $40 \mu \mathrm{m}$ to $250 \mu \mathrm{m}$ size fractions, and by an Xradia XRM500 Versa instrument (Carl Zeiss X-ray Microscopy) for the $4 \mu \mathrm{m}$ to $25 \mu \mathrm{m}$ size fractions. The image size, pixel size, and number of analysed particles are listed in Table 5. The resulting 3 -D image, made by stacking the many 2-D images of the sample, is a gray-scale image that needs to be segmented to produce the final 3-D image. In the segmented 3-D digital image, details below the voxel size are lost, and it is possible that the volume of the particles in the image could be a little smaller or a little larger than reality, due to the choice of threshold used in the segmentation process. However, for larger particles whose volumes could be easily experimentally measured, this technique did give an accurate value (1\% to $2 \%$ uncertainty) of particle volume [25]. There can be errors in the surface area due to "ringing" effects in the actual spherical harmonic coefficients themselves, akin to the Gibbs' phenomenon in 2-D Fourier series [44], [45], but these errors for random particles are small. The main point of using spherical harmonic-based surface areas in this paper is to provide a way to take into account the effect of shape on surface area, since most experimental methods assume the particles are perfect spheres when their particle data is analysed. Spherical harmonic functions [23] were generated using the $\mu \mathrm{CT}$ data for each of the analysed particles. By using those functions, one can compute any geometric quantity of the particle that can be defined by integrals over the volume or over the surface or any other algorithm using points on the particle surface or within the particle volume, 
since the spherical harmonic approach estimates the particle shape by an analytical, differentiable mathematical function [23], [44], [45].

Table 5: $\mu \mathrm{CT}$ and spherical harmonic analysis - image size, pixel size and number of analysed particles.

\subsubsection{DIA method}

The DIA technique approach used the Fine Particle Analyser (FPA) equipment by AnaTec [46]. During the analysis, a crushed powder sample was placed into a feeding funnel and dispersed by compressed air at $200 \mathrm{kPa}$ pressure. 2-D images of the free falling particles were taken by a highspeed camera at a pixel size of $4.29 \mu \mathrm{m}$. The 2-D filler particle projections were then analysed by image analysis software provided by the equipment producer to compute a wide range of statistical and geometrical parameters. Particle size was described by the equivalent area circle diameter $(\mathrm{DA}=$ diameter of a circle with an area equal to the area of the 2-D projection of particle). At least 260000 particles were analysed for each of the samples.

The repeatability precision of the instrument for the same sample analysed in replicate sequential runs was determined to be well within a $\pm 1 \%$ standard deviation of the cumulative percent value for each size subclass. A significantly higher degree of variation (up to a standard deviation of $1.9 \%$ ) was observed when several subsamples were obtained from the same sample.

\subsection{5. $\mathrm{N}_{2}$ adsorption BET method analysis}

Specific surface area measurements were performed using BET nitrogen adsorption isotherms [27]. Sample preparation included oven-drying at $105{ }^{\circ} \mathrm{C}$ for $24 \mathrm{~h}$ prior to measurements. The sources of greatest uncertainty for the BET method have been identified [47] to be liquid nitrogen level control, sample preparation conditions and sample mass measurement. Those together are estimated [47] to cause an uncertainty of about $0.6 \%$ in the measured BET specific surface area.

\section{RESULTS AND DISCUSSION}

\subsection{Particle size distribution}


Figure 2 and Figure 3 present cumulative PSDs of all the analysed samples split into the three distinct size ranges, as determined by the XS method. It can be seen from the results that the shape of the measured grain size distributions are similar but over different particle size ranges. For all three size groups, the T8 rock type fines are the finest, while the T9 fines are the coarsest. The curves for these rock types have been accordingly shown in black colour in the charts in Figure 2 and Figure 3. PSDs of the fines from these two rock types (T8 and T9) were chosen for further comparison (Figure 4) with the results from the other analysis methods.

For easier interpretation of the results shown in Figure 4, the expected smallest detectable particle sizes and analysed characteristic size-related properties are summarised in Table 6. By taking into consideration the data from Table 6, it is evident that the limitations of the various methods have to be considered when discussing the results in Figure 4.

Table 6: Smallest detectable particle sizes and measured characteristic properties of the particles.

Figure 2: PSD of the crushed aggregate fines materials, as determined by XS. The curves of the finest and coarsest samples for each size fraction have been shown in black. (a) $4 \mu \mathrm{m}$ to $25 \mu \mathrm{m}$ fractions; (b) $20 \mu \mathrm{m}$ to $60 \mu \mathrm{m}$ fractions.

Figure 3: PSD of the crushed aggregate fines materials in the $40 \mu \mathrm{m}$ to $250 \mu \mathrm{m}$ fraction, as determined by XS. The curves of the finest and coarsest materials are shown in black.

It can be seen from Figure 4 that the DIA method seems to yield coarser particle size distributions (in particular for particles smaller than $200 \mu \mathrm{m}$ ) than obtained by the other methods. This has been observed in a previous study [7]. However, this observation is not surprising because for the DIA method no registered particles in the finest part ( $\leq$ approx. $5 \mu \mathrm{m}$ ) of the grading are expected due to the resolution of the method, which in Table 6 is listed as $4.29 \mu \mathrm{m}$. Discrepancies between methods can also occur due to the different mathematical correlations between the measured size-related characteristics and the reported particle dimension or due to different levels of particle dispersion. With respect to the latter, insufficient dispersion would result in smaller particles adhering to the surface of the larger and/or to each other, thus artificially coarsening the PSD. This can, however, be expected to be a problem only for particles smaller than about $1 \mu \mathrm{m}$, because Pugh and Bergström [48] have estimated that the van der Waals attraction, electrostatic interaction and Brownian motion energy of particles in a 
suspension is about on the same order of magnitude as the kinetic energy of stirring for particles of about $1 \mu \mathrm{m}$ equivalent size, while the kinetic energy of stirring is at least two orders of magnitude higher for particles of about $10 \mu \mathrm{m}$ equivalent size. For particles of $0.1 \mu \mathrm{m}$ equivalent size, the van der Waals attraction, electrostatic interaction and Brownian motion energy of particles in a suspension has been estimated [48] to be an order of magnitude higher than the possible kinetic energy of stirring.

Different mathematical correlations between the measured size-related characteristics and the reported particle dimension can be discussed by comparing the principles of DIA and $\mu \mathrm{CT}$ analysis. The DIA method registers one $2 \mathrm{D}$ projection of an irregular particle and then reports the size as the diameter of a circle with the same area as the registered projection. $\mu C T$ PSD analysis is volume-based and so the diameter of a sphere with the same volume as the measured particle is reported as the size parameter, although measures of size can be used. If the DIA and $\mu \mathrm{CT}$ analysis were both applied to a perfect sphere, the same result will be obtained - the diameter of the sphere. However, if particles become more oblate (as can be expected from crushed aggregate fillers [7], [14]) at the same volume, departure from this relationship can be expected. This is because the volume-based $\mu \mathrm{CT}$ method will still yield the same result; while the projection based 2-D method will yield higher equivalent particle size for projections when the two longer axes are aligned in the plane of projection. Projections when the two shortest axes are aligned in the plane of projection will yield lower equivalent particle size. Determining whether the probability of particle orientation is completely random is not straightforward. However, given that in the DIA equipment the particles are dispersed by a compressed (200 kPa) air-stream, which flows parallel to the plane of projection, it can be expected that most of the particles have their longest axis aligned in the direction of air-flow [49].

The rest of the test methods can be compared in a similar way. For example, PSDs above 100 $\mu \mathrm{m}$ reported as part of the XS curves, have in fact been determined by conventional dry-sieving. Good agreement has been observed among the 3-D $\mu \mathrm{CT}$ scanning results, results from an average of 2-D projections, and dry-sieving results for crushed concrete aggregates of size $20 \mu \mathrm{m}$ to $38 \mathrm{~mm}$ [25] and glass beads [50] of size $0.15 \mu \mathrm{m}$ to $2000 \mu \mathrm{m}$, if different linear single shape parameters than those in Figure 4 are used. For 3-D $\mu \mathrm{CT}$ measurements, this includes finding a rectangular box with dimensions- length (L), width (W), and thickness (T), that just encloses the 
particle. The width (W) can then be related to the dry-sieving results. For the particle projections in the 2-D DIA images, a length parameter $\mathrm{X}_{\mathrm{c}, \mathrm{min}}$ is shown to be related to the 3-D measurement width (W) and consequently dry-sieving particle size. $\mathrm{X}_{\mathrm{c}, \min }$ for a given 2-D image of a particle is defined as the shortest chord of the measured set of maximum chords of a particle projection. Erdoğan et al. [14] have shown that when the LD results are compared to those obtained by $\mu \mathrm{CT}$ and spherical harmonics, the length (L) 3-D size parameter will yield the best correlation between $\mathrm{LD}$ and $\mu \mathrm{CT}$.

Figure 4: PSD of the crushed aggregate fines determined by different methods. Results for the T8 series filler fractions (a) 4 to $25 \mu \mathrm{m}$, (c) 20 to $60 \mu \mathrm{m}$, and (e) 40 to $250 \mu \mathrm{m}$. Results for the T9 series filler fractions (b) 4 to 25 $\mu \mathrm{m}$, (d) 20 to $60 \mu \mathrm{m}$, and (f) 40 to $250 \mu \mathrm{m}$.

The discussion above shows that particle size is indeed a property that is defined by the measuring technique used. As a result, the particle size distributions obtained by different methods in Figure 4 show discrepancies between each other. While successful attempts have been reported to normalise some of these methods so that the PSD curves show a better agreement [14], the choice of the most useful method will depend on the application, since absolute accuracy is not obtainable at present. For crushed aggregates fines for use in concrete, this would mean that the analysed particle characteristics should be applicable for concrete proportioning. It has been shown that the behaviour of crushed fines in fresh concrete is to a large extent governed by their specific surface area [4], [9], [10], [11], [6]. Thus, the applicability of the different methods for determining this characteristic is further discussed.

\subsection{Specific surface area}

Specific surface area, in contrast to the particle size distribution, is expressed with a single number, which makes it more easily applicable for modelling the performance of crushed fines in concrete. PSDs can be used to calculate the specific surface area value by dividing the size distribution into a finite amount of bins and assuming equivalent spherical or other diameters of particles that correspond to the mean size of each bin. This data set then allows the plotting of the differential distribution of specific surface area among different particle size ranges (Figure 5 and Figure 6). Such an attempt [7] on similar crushed aggregate powders, which included the 
very smallest particles up to a maximum size of $125 \mu \mathrm{m}$, suggested that nearly $90 \%$ of the specific surface area was concentrated in the particle size range below $20 \mu \mathrm{m}$ and more than 50 $\%$ below $5 \mu \mathrm{m}$. This is because the ratio of surface area to volume isinversely proportional to particle size [11]. Calculations of the differential distributions of the specific surface of the fines are reported in Figure 5 for the $4 \mu \mathrm{m}$ to $25 \mu \mathrm{m}$ fraction (denoted Tn-1, $\mathrm{n}=1,10$ ) PSDs determined by the XS method and in Figure 6 for the same size range of particles where the PSDs have been determined by the LD method. Slightly different bins are used for the plots, based on output from the XS and LD equipment. For the XS data, the following bin sizes have been used for the plot: eight $5 \mu \mathrm{m}$ wide bins in the size range of $10 \mu \mathrm{m}$ to $50 \mu \mathrm{m}$, along with bins between $8 \mu \mathrm{m}$ and 10 $\mu \mathrm{m}, 6 \mu \mathrm{m}$ to $8 \mu \mathrm{m}, 5 \mu \mathrm{m}$ to $6 \mu \mathrm{m}, 4 \mu \mathrm{m}$ to $5 \mu \mathrm{m}, 3 \mu \mathrm{m}$ to $4 \mu \mathrm{m}, 1.5 \mu \mathrm{m}$ to $2 \mu \mathrm{m}, 1 \mu \mathrm{m}$ to 1.5 $\mu \mathrm{m}$, and $0 \mu \mathrm{m}$ to $1 \mu \mathrm{m}$. For the LD results, 38 bins between for sizes between $0.5 \mu \mathrm{m}$ and $58 \mu \mathrm{m}$, with bin sizes that start at $0.06 \mu \mathrm{m}$ at the small particle end and increase up to $6.7 \mu \mathrm{m}$ at the large particle end of the range, have been used. The vertical axis shows the percentage of the total specific surface area found for particles in a given bin.

The plots in Figure 5 show that a very large portion of the specific surface area of the analysed fractions of fines is concentrated in the size range below about $5 \mu \mathrm{m}$ in size as anticipated. This portion is about $50 \%$ for the XS results and $60 \%$ for the LD results. This means that the determined specific surface values will be strongly dependent on the PSD results in the size range below about $5 \mu \mathrm{m}$. Furthermore, results below about $1 \mu \mathrm{m}$ in size can be even more important for the specific surface area, due to the relatively high specific surfaces of the particles in this size range. It can, for example, be seen from Figure 4(a) that the XS method reports a very high content of particles smaller than $1 \mu \mathrm{m}$ for the T8-1 material, which subsequently results in very high differential specific surface of these grains, as reported in Figure 5(a). This suggests that only the PSD measurement methods that allow accurate measurements of particles below about $5 \mu \mathrm{m}$ and down to at least $1 \mu \mathrm{m}$ are suitable for determining the specific surface area of crushed aggregate fines over the entire particle size range. From the measurement methods included in this study, only the XS and LD methods can thus hope to possess the required resolution.

Figure 5: Differential \%, by mass, distribution of the specific surface within the bins used to determine the total specific surface area from the $4 \mu \mathrm{m}$ to $25 \mu \mathrm{m}$ fraction PSD results obtained by the XS method. 
Figure 6: Differential \%, by mass, distribution of the specific surface within the bins used to determine the total specific surface area from the $4 \mu \mathrm{m}$ to $25 \mu \mathrm{m}$ fraction PSD results obtained by the LD method.

Results presented in Figure 4a and Figure 4b show that the PSDs of the crushed fines determined by XS and LD in the range of particles smaller than $5 \mu \mathrm{m}$ are different, which then strongly affects the calculations of the differential specific surface (Figure 5). For example, for the T8-1 fines the XS method has registered $6.1 \%$ by mass of particles smaller than $1 \mu \mathrm{m}$, while the LD method has registered only $2.9 \%$ by mass. It can also be seen that for the T9-1 fines the XS method has reported $8.6 \%$ by mass of particles smaller than $3 \mu \mathrm{m}$, while the LD has registered none of the particles being smaller than the given size. Discrepancies at this range of particle size can also be observed among most of the other fine materials analysed by both of the methods. This discrepancy has been reported for similar crushed aggregate materials [7].

To determine which of the two methods, XS or LD, would be more suitable for obtaining accurate approximations of the specific surface area of crushed aggregates fines, one would need to be able to identify which one of them is more accurate in the very fine range. This is, however, not a straightforward task, because "ground truth" can only be obtained by the aid of microscopy. Automated scanning electron microscopy (ASEM) can be used to rapidly investigate thousands of very fine particles, but still only using 2D images [51], [52], [53].

It can, however, be demonstrated that more uncertainty with respect to registering particle size in the very fine range is present for the LD analysis. As introduced in Section 2.2.1, analysis using the Mie optical model requires knowing the light absorption properties of the particles, in particular the imaginary refractive component $(\mathrm{k})$. The precise value of $\mathrm{k}$ is very important for determining the PSD of particles below $1 \mu \mathrm{m}$ in size. As reported, $\mathrm{k}=0.1$ was chosen for the analysis of the crushed fines; however, in practice this number can be different and is difficult to determine. Figure 7 illustrates the sensitivity of the resulting PSD for the T8-1 and T9-1 fines, when the real part of the complex refractive index is kept fixed, while the imaginary part is varied from 0.01 to 1.0 in three steps. The results show an obvious deviation between curves obtained with different k-values for particle sizes below about $30 \mu \mathrm{m}$. The difference is more pronounced in the very fine part of the curves (below about $3 \mu \mathrm{m}$ to $5 \mu \mathrm{m}$ ). This indicates that 
the choice of an unsuitable imaginary component of the complex refractive index can result in a considerable overestimation or underestimation of the actual volume of the very fine particles. Results from Table 7 show that for the analysed fines the choice of a different value of $k$, either greater than or less than $\mathrm{k}=0.1$, can cause changes in the calculated specific surface area of the order of $30 \%$. This indicates that the specific surface area determined by LD includes a considerably high level of uncertainty than does the XS results due to the difficulties with determining the correct input parameters for the analysis.

Figure 7: Sensitivity of calculated PSD to variation in imaginary component (k) of complex refractive index (m) for: (a), (c) - aggregate fines T8-1; (b), (d) - aggregate fines T9-1.

Table 7: Sensitivity of the calculated specific surface values on the chosen imaginary component $(\mathrm{k})$ of the complex refractive index $(\mathrm{m})$.

PSD measurements with the XS method will normally not include a high amount of uncertainty due to the difficulties associated with determining input parameters necessary for the mathematical analysis. This is because, as introduced in Section 2.2.2, the only input property necessary for the analysis is particle density. This can be easily measured with the aid of gas pycnometry or at least estimated from the known values of the coarser aggregate particles. Still, the XS method can have limitations with respect to its ability of correctly detecting particles below about $1 \mu \mathrm{m}$ in size [15], even though the vendor claims that the resolution is down to 0.1 $\mu \mathrm{m}$ (Table 6). The uncertainties for particles below $1 \mu \mathrm{m}$ in size are related to Brownian motion phenomena [15] that has been reported [43] to widen the PSD of monosized particle samples of size below $1 \mu \mathrm{m}(0.2$ and $0.5 \mu \mathrm{m})$, because of the random Brownian movement in addition to the gravitational settling. A measurement artefact occurs because very small particles are registered both higher and lower in the measurement cell than could be expected based only on their Stokesian diameter. It can thus be anticipated that this phenomenon can result in overestimation of the volume of the very fine particles in a wide continuous grading, because some of the particles will be detected multiple times. This phenomenon has been reported in [16], where four different methods (including XS, Electrozone Particle Counter, LD and pipet method) were applied to analyse the PSD of several fine silt and clay sediments from lakes, with approximately $90 \%$ of the material less than $10 \mu \mathrm{m}$ in size. The XS method consistently yielded the finest distributions due to many more particles registered to be finer than $1 \mu \mathrm{m}$ in comparison to the 
other methods. Similar outcomes have been obtained by others [17], [18] in analysis of natural clay-sized samples, where $20 \%$ or more, by mass, clay (particles $\leq 2 \mu \mathrm{m}$ ) were detected by the XS method in comparison to the other methods used (LD, Electrozone Particle Counter, hydrophotometer and Atterberg method). The authors of references [17] and [18] related the higher clay content to the use of a high volume concentration of particles in the XS (volume fraction of 0.02 to 0.03 ), so that the resulting particle-to-particle interaction hindered settling.

Norwegian crushed aggregates do not usually contain clay minerals. However, XRD analysis ( Table 2) indicated that some of the fines contained chlorite, a clay mineral. For most of these, the amounts were relatively small ( $0.2 \%$ to $2.6 \%$ by mass), while the basalt fines, T8- $1, \mathrm{~T} 8-2$ and T8-3, have been determined to include $20.2 \%, 13.0 \%$ and $13.2 \%$ by mass of chlorite minerals, respectively, and the mylonittic quartz diorite fines, T1-1, T1-2 and T1-3, have been determined to include $11.3 \%, 6.8 \%$ and $5.9 \%$, respectively. By looking at the XS results in Figure 2 and Figure 3, it is evident that the highest number of particles smaller than $1 \mu \mathrm{m}$ was detected for the three basalt powders. On the other hand, no particles finer than $1 \mu \mathrm{m}$ were found for the mylonittic quartz diorite fines. This might be the result of different mechanical properties and textures of the parent rocks that result in different liberation of the chlorite minerals during crushing. For example, the basalt is typically a fine-grained rock with open pores. Chlorite and other such minerals will commonly be concentrated in these pores and hence might be more exposed during crushing and dispersion of the rock.

The above discussion provides a possible cause for the high amount of particles finer than $1 \mu \mathrm{m}$ registered in the basalt crushed fines. However, as demonstrated in Figure 5, the high amount of these particles can cause a tremendous effect on the calculated specific surface area. The important question is then whether the determined particles are real or whether a considerable amount are non-existent "ghost particles", as was the case when choosing an inappropriate complex refractive index (k) for LD measurements (Figure 7). First, it was attempted to physically observe these very fine particles. A simple sedimentation experiment, consisting of pouring a powder sample into water-filled, transparent PMMA columns, was performed. Three of the coarsest ( $40 \mu \mathrm{m}$ to $250 \mu \mathrm{m}$ ) fine fractions including the basalt fines, i.e. T3-3, T4-3 and T8-3, were observed simultaneously. Figure 8 shows pictures of the sedimentation columns taken at different points of time. It was seen that after $5 \mathrm{~min}$, the water in the column with the 
anorthosite T4-3 fines was completely clear, the column with T3-3 fines seemed to have very few particles still suspended, while the column with the basalt fines still seemed to have many more of its particles suspended in water. It can also be observed that there exists a clear borderline between the water and the sediment of particles at the bottom of the column for fines T3-3 and T3-4, while the borderline is blurry for the basalt T8-3 fines. The situation after $1 \mathrm{~h}$ is similar; with the qualitative visual impression that the water in both the T3-3 and T8-3 columns had become more transparent. There still seemed to be more particles suspended for the T8-3 basalt fines. Finally, all particles had settled after $48 \mathrm{~h}$ of settling time. These observations support the conclusion that much finer particles are present in the basalt T8-3 fines, as indicated by the measured PSDs in Figure 3. So therefore, as seen from Figure 8, there exists evidence that the very fine particles in the basalt crushed fines really exist. However, it is still necessary to justify whether their amount has not been overestimated, as reported in [16], [17], [18], which is a more difficult task, due to lack of a "ground truth" reference.

Figure 8: Transparent PMMA sedimentation columns (diameter of $80 \mathrm{~mm}$ ) at different points of time after introduction of fines.

In Figure 9, the specific surface area for all 30 crushed fines determined by both sedimentation and LD methods have been related to the corresponding specific surface area values as determined by the nitrogen BET method. It is clear from these results that the values obtained by the BET method are in general an order of magnitude higher than those calculated from the particle size distributions. This has already been reported before for similar materials in [7]. One reason for the much higher BET surfaces is the open porosity of the crushed powders, because the gas adsorption-based BET measurements include not only the external but also the open internal specific surface area of the crushed aggregate particles. Thus they can be strongly affected by fine porosity of the fines, which can result from weathering, interfaces between individual minerals or crystal grains, or the presence of layered minerals like micas [7]. Fine surface texture of the particles, not sensed by the PSD measurements but seen by the BET method, might also give an increase. Therefore, Cepuritis et al. [7] have suggested not using the BET method for comparing the specific surface area of aggregate fines with different mineralogy. 
The effect of the internal surface can be estimated by measuring water absorption values of rock types with similar pore diameters. This is because higher internal pore volume at similar pore size will result in higher specific surface area of the internal pore walls. Results of such measurements according to EN 1097-6 [54] on the $0.063 \mathrm{~mm}$ to $2 \mathrm{~mm}$ fractions of all 10 rock types used for producing the crushed fines included in this study are summarised in Table 8 . The results suggest that the basalt rock type has the highest measured internal porosity volume, which coincides with its higher BET specific surface (Figure 9). Given that the internal pore sizes of the fine powder materials are unknown, it is difficult to use the BET measurement results to clearly see if the volume of particles finer than $1 \mu \mathrm{m}$ in the basalt powders was over or underestimated by the PSD methods. Further studies to clarify the roles of increased external surface area due to particle actual shape vs. inner surface area due to mineralogy could perhaps be investigated by use of AFM to get measurements of the "nano- roughness" of the different surfaces.

Table 8: Water absorption values of $0.063 \mathrm{~mm}$ to $2 \mathrm{~mm}$ fractions of the rocks used for obtaining the crushed filler samples.

According to EN 1097-6, the uncertainties for the measurements of water absorption depends on the pycnometer calibration, the choice of liquid used, and the type of material tested. Based on cross-testing results [54] for normal weight aggregates (density of about $2.7 \mathrm{~g} / \mathrm{cm}^{3}$ ), the precision of the method has been estimated to be in the range of $0.5 \%$ (repeatability) and $1.2 \%$ (reproducibility).

Still, a higher number of the fine particles, as for example registered for the $\mathrm{T} 8$ basalt powders (Figure 2 and Figure 3) should be, at least to some extent, reflected in the BET measurements. This can indeed be observed in Figure 9, where a much better (however still limited) overall correlation is observed between the XS values and the BET specific surfaces, as compared to the LD results (Figure 9a and b). This is another indication that the sedimentation method gives more accurate results, compared to LD, for both PSD and specific surface area of crushed aggregate fines that are smaller than about $5 \mu \mathrm{m}$.

Figure 9: Correlation between specific surface values of the aggregate fines as determined by BET method and (a) X-ray sedimentation; (b) wet-method laser diffraction. 
The $\mu \mathrm{CT}$ and spherical harmonics measurement data set obtained in this study can also be used to estimate the specific surface area of crushed fines, in the size range of this technique. This then also gives an estimate of the error introduced in the calculations by assuming spherical particle shape compared to the numerically integrated surfaces and volumes for each particle from the spherical harmonics functions. This is illustrated by plots of the ratio of the true particle surface area (SA) to the surface area of the equivalent sphere (VESD SA) vs. the diameter of the equivalent sphere. Plots for the three series of particles corresponding to rock types T8 and T9 are presented in Figure 10. The ratio, SA/ VESD SA, will be a constant value equal to unity only for a spherical particle, and since the sphere is the minimum surface area particle for a given volume [55], increasing non-sphericity is shown by higher values of this parameter. The obtained values seem to range between 1 to 1.7. Some examples of 3-D images (created with Virtual Reality Modelling Language, VRML) of the actual particles based on the spherical harmonic method of approximating the shape [14], [23] are shown in Figure 11 and Figure 12 for T8 and T9 rock type fines with the extreme SA/VESD SA values (close to 1 and 1.7).

In the data presented in Figure 10, there seems to be a trend towards slightly higher values of the dimensionless SA/ VESD SA ratio for smaller equivalent spherical diameters, indicating that the very small crushed particles are somewhat more non-spherical than the larger particles. However, if the average values of the SA/ VESD SA ratios are calculated for all the analysed particles for all the crushed fine powder samples (

Table 9), it is evident that very similar values are obtained for all the rock types. These result suggest that for acrushed filler material of the same size range, assuming spherical particle shape introduces an underestimation of the specific surface area of similar magnitude for all 10 rocks and that the multiplicative shape effect on surface area is about 1.25 to 1.3 and 1.19 to 1.23 for the finest and the two coarsest filler fractions, respectively. This finding is important and simplifies specific surface area determination for crushed aggregate fines for concrete proportioning purposes and quality control at aggregates quarries. This is because the specific surface area can be obtained with a good precision from sedimentation PSD analysis results and simple calculation by assuming a spherical particle shape. If an accurate absolute value is necessary, it is recommended to multiply the obtained specific surface values with a factor of 1.2 for particles smaller than about $20 \mu \mathrm{m}$ of equivalent size and a factor of 1.3 for crushed filler particles larger than about $20 \mu \mathrm{m}$ equivalent size. 
Figure 10: Relation between actual surface area of particles as determined by $\mu \mathrm{CT}$ and spherical harmonics and specific surface of a volume equivalent sphere as a function of diameter of the equivalent sphere.

Figure 11: 3-D VRML images of selected particles from T8 rock types crushed fines based on the results from $\mu \mathrm{CT}$ scanning and spherical harmonic analysis; (a), (b) VESD=7.24 $\mu \mathrm{m}$, SA/ VESD SA=1.083; (c), (d) VESD=3.80 $\mu \mathrm{m}$, $\mathrm{SA} / \mathrm{VESD} \mathrm{SA}=1.592$; (e), (f) VESD=131.48 $\mu \mathrm{m}$, SA/ VESD SA=1.034; (g), (h) VESD=131.89, SA/ VESD $\mathrm{SA}=1.625$.

Figure 12: 3-D VRML images of selected particles from T9 rock types crushed fines based on the results from $\mu \mathrm{CT}$ scanning and spherical harmonic analysis; (a), (b) VESD=7.56 $\mu \mathrm{m}$, SA/ VESD SA=1.096; (c), (d) VESD=6.02 $\mu \mathrm{m}$, $\mathrm{SA} / \mathrm{VESD} \mathrm{SA}=1.619$; (e), (f) VESD=132.73 $\mu \mathrm{m}$, SA/ VESD SA=1.038; (g), (h) VESD=136.34, SA/ VESD $\mathrm{SA}=1.691$.

Table 9: Average ratio of actual surface area of particles as determined by $\mu \mathrm{CT}$ and spherical harmonics and specific surface area of volume equivalent sphere.

\section{DISCUSSION AND CONCLUSIONS}

The particle size distributions of the analysed crushed rock fillers in this paper are similar to some natural mineral sediment materials that have been previously analysed with different PSD determination methods, as reported in geological science literature [15], [16], [17], [18]. Review of [15], [16], [17], [18] indicates that there are also other methods that could be applied to crushed concrete aggregate powder analysis (e.g., Electrozone Particle Counter, hydrophotometer, Atterberg method, and pipet method).

For crushed aggregate fines passing $125 \mu \mathrm{m}$ or $63 \mu \mathrm{m}$ sieves, generally about $50 \%$ of the surface area is concentrated among particles below about $5 \mu \mathrm{m}$ equivalent sphere size. Particles smaller than $1 \mu \mathrm{m}$ equivalent sphere diameter were detected in some of the materials; however, their total amount was difficult to reliably determine. Since such a large amount of the specific surface area comes from small particles, this suggests that only the PSD measurement methods that allow measurements of particles below about $5 \mu \mathrm{m}$ and down to at least $1 \mu \mathrm{m}$ are suitable for determining the specific surface area of crushed aggregate fines over the entire expected particle size range. Only two of the methods considered, X-ray sedimentation and laser 
diffraction, could sense particles in this size range. The X-ray sedimentation method seemed to be the best for this purpose due to fewer uncertain input parameters, The laser diffraction method could introduce an error of up to about $30 \%$ in the approximated specific surface area values due to uncertainties in the imaginary part of the index of refraction needed for Mie theory analysis at smaller particle sizes.

However, in some cases, X-ray sedimentation analysis seemed to overestimate the amount of particles smaller than about $1 \mu \mathrm{m}$. This is expected to be the result of Brownian motion, particleto-particle interaction or hindered settling that can become dominant for particles in this size range. This effect will only be noticeable if these very small particles are present in the crushed fines, which is a function of the parent rock mineralogy, texture and mechanical properties. The basalt sample was an example, with chlorite inclusions being a possible source of fine particles. For future research, it is recommended to explore the possibilities of applying a centrifugal sedimentation method for more precise measurements in the range below $1 \mu \mathrm{m}$. This is because the centrifugal sedimentation method is reported to allow for speeding up the settling process of the very small sub-micrometer range particles, which may reduce the error introduced by the hindered settling process for very small particles that can bias X-ray sedimentation results [21].

The results of this paper also indicated that for crushed fines produced in the same way from rocks with vastly different mineralogy, the underestimation error introduced due to assuming spherical particle shape for surface area approximation is of surprisingly similar magnitude, 20 $\%$ to $30 \%$. The recommendation is made that in order to determine accurate absolute specific surface areas for crushed fines, the results obtained from PSD calculations by assuming spherical shape must be adjusted upward by $20 \%$ for particles smaller than about $20 \mu \mathrm{m}$ of equivalent size and $30 \%$ for crushed filler particles larger than about $20 \mu \mathrm{m}$ of equivalent size.

\section{ACKNOWLEDGEMENTS}

This work is based on research performed in COIN - Concrete Innovation Centre (www.coinweb.no) - which is a Centre for Research based Innovation, initiated by the Research Council of Norway (RCN) in 2006. The authors would like to gratefully acknowledge COIN for 
financial support and for facilitating the interaction between research and industry. The authors would like to acknowledge AnaTec (now part of Microtrac) for their in-kind contribution and help with the DIA measurements. The authors would also like to acknowledge Dr. Kenneth Snyder, the Deputy Division Chief of the Materials and Construction Research Division at the National Institute of Science and Technology (NIST), for facilitating the collaboration between the Norwegian University of Science and Technology and NIST.

\section{REFERENCES}

[1] European Committee for Standardization, "Tests for geometrical properties of aggregates Part 1: Determination of particle size distribution - Sieving methods.," CEN, Brussels, 2012.

[2] American Society for Testing and Materials, "ASTM C136-06 Standard Test Method for Sieve Analysis of Fine and Coarse Aggregates," ASTM, Pennsylvania, 2006.

[3] European Committee for Standardization, "Tests for geometrical properties of aggregates Part 10: Assessment of fines. Grading of filler aggregates (air jet sieving)," CEN, Brussels, 2009.

[4] E. Mørtsell, Modelling the effect of concrete part materials on concrete consistency. PhD, Norwegian University of Science and Technology (In Norwegian).

[5] M. Westerholm, B. Lagerblad, J. Silfwerbrand and E. Forssberg, "Influence of fine aggregate characteristics on the rheological properties of mortars," Cement and Concrete Composites, vol. 30, no. 4, p. 274-282, 2008.

[6] R. Cepuritis, S. Jacobsen and B. Pedersen, "SCC matrix rheology with crushed aggregate fillers: effect of physical and mineralogical properties, replacement, co-polymer type and w/b ratio.," in Electronic proceedings of the 7th international RILEM symposium on Selfcompacting concrete, Paris, 2013.

[7] R. Cepuritis, B. J. Wigum, E. Garboczi, E. Mørtsell and S. Jacobsen, "Filler from crushed aggregate for concrete: Pore structure, specific surface, particle shape and size distribution," Cement and Concrete Composites, vol. 54, pp. 2-16, 2014. 
[8] B. Wigum, S. Danielsen, O. Hotvedt and B. Pedersen, "Production and utilisation of manufactured sand. COIN project report 12-2009," SINTEF, Trondheim, 2009.

[9] B. Pedersen, Alkali-reactive and inert fillers in concrete. Rheology of fresh mixtures and expansive reactions.PhD, Norwegian University of Science and Technology, 2004.

[10] B. Pedersen and E. Mørtsell, "Characterisation of fillers for SCC," in The Second International Symposium on Self-Compacting Concrete, 23-25 October, Tokyo, 2001.

[11] O. Esping, "Effect of limestone filler BET(H2O)-area on the fresh and hardened properties of self-compacting concrete," Cement and Concrete Research, vol. 38, no. 7, pp. 938-944, 2008.

[12] P. Heikki, "Effect of fines on properties of concrete.," Nordisk Betong, vol. 3. (In Norwegian), 1967.

[13] H. Järvenpää, "Quality characteristics of fine aggregates and controlling their affects on concrete. PhD," Helsinki University of Science and Technology, 2001.

[14] S. T. Erdoğan, E. J. Garboczi and D. W. Fowler, "Shape and size of microfine aggregates: X-ray microcomputed tomography vs. laser diffraction," Powder Technology, no. 177, pp. 53-63, 2007.

[15] J. P. M. Syvitski, Principles, methods, and Application of Particle Size Analysis, Cambridge: Cambridge University Press, 1997.

[16] F. Schiebe, N. Welch and L. Cooper, "Measurement of Fine Silt and Clay Size Distributions," Transactions of the ASAE, vol. 26, no. 2, pp. 491-496, 1983.

[17] R. Stein, "Rapid grain-size analyses of clay and silt fraction by SediGraph 5000D: Comparision with Coulter Counter and Atterberg methods.," Journal of Sedimentary Petrology, vol. 55, no. 4, pp. 590-593, 1985.

[18] J. Singer, J. Anderson, M. Ledbetter, I. J. K. McCave and R. Wright, "An assessment of analytical techniques for the size analysis of fine-grained sediments.," Journal of Sedimentary Petrology, vol. 58, no. 3, pp. 534-543, 1988.

[19] V. Buhrke, R. Jenkins and D. Smith, A practical guide for the preparation of specimens for X-ray fluorescence and X-ray diffraction analysis, New York: Wiley-VCH, 2001.

[20] K. Hestnes and B. Sørensen, "Evaluation of quantitative X-ray diffraction for possible use in the quality control of granitic pegmatite in mineral production," Minerals Engineering, 
vol. 39, pp. 239-247, 2012.

[21] T. Allen, Powder Sampling and Particle Size Determination, Amsterdam: Elsevier, 2003.

[22] H. Merkus, Particle Size Measurements. Fundamentals, Practice, Quality., Dordrecht: Springer Science+Business Media B.V., 2009.

[23] E. J. Garboczi, "Three-dimensional mathematical analysis of particle shape using X-ray tomography and spherical harmonics: application to aggregates used in concrete," Cement and Concrete Research, vol. 32, no. 10, pp. 1621-1638, 2002.

[24] S. T. Erdoğan, P. N. Quiroga, D. W. Fowler, H. A. Saleh, R. Livingston, E. J. Garboczi, P. M. Ketcham, J. G. Hagedorn and S. G. Satterfield, "Three-dimensional shape analysis of coarse aggregates: New techniques for and preliminary results on several different coarse aggregates and reference rocks," Cement and Concrete Research, no. 36, pp. 1619-1627, 2006.

[25] M. A. Taylor, E. J. Garboczi, S. T. Erdoğan and D. W. Fowler, "Some properties of irregular 3-D particles," Powder Technology, no. 162, pp. 1-15, 2006.

[26] G. J. Edward and H. Azari, "National Cooperative Highway Research Program 20-07 (243): Development of Glass Beads Utilised in Traffic Markings," Transportation Research Board, Washington, 2010.

[27] G. Fagerlund, "Determination of specific surface by the BET method," Materials and Structures, vol. 6, no. 3, pp. 239-245, 1986.

[28] Malvern Instruments, "Mastersizer 2000 User Manual. MAN0384 Issue 1.0 March,” Malvern Instruments, Worcestershire, 2007.

[29] V. A. Hackley, L.-S. Lum, V. Gintautas and C. F. Ferraris, "Particle Size Analysis by Laser Diffraction Spectrometry: Application to Cementitios Powders," NIST, Gaithersburgh, 2004.

[30] P. E. Plantz, "A Conceptual, Non-Mathematical Explanation on the Use of Refractive Index in Laser Particle Size Measurement.," 2008. [Online]. Available: http://www.microtrac.net/MTWP/wp-content/uploads/2012/10/Microtrac-ApplicationNotes-Understanding-the-Concept-of-Refractive-Index-and-the-Effect-of-ParticleShape.pdf. [Accessed 2708 2014].

[31] ISO, "ISO 13320-1:1999(E), Particle size analysis - LASER diffraction methods - Part 1: 
General principles,” International Organization for Standardization, Geneva, 1999.

[32] D. Lide (ed.-in-chief), Handbook of Chemestry and Physics. 78th edition, New York: CRC Press, 1997.

[33] E. D. Palik (ed.), Handbook of Optical Constants of Solids, London: Academic Press, 1998.

[34] Mindat, "Labradorite," [Online]. Available: http://www.mindat.org/min-2308.html. [Accessed 2408 2014].

[35] Mindat, "Microcline," [Online]. Available: http://www.mindat.org/min-2704.html. [Accessed 2808 2014].

[36] J. Lindberg, R. Douglass and D. Garvey, "Absorption-coefficient-determination method for particulate materials," Applied Optics, vol. 33, no. 9, pp. 4314-4319, 1994.

[37] N. Marley, J. Gaffney, J. C. Baird, C. Blazer, P. Drayton and J. Frederick, “An empirical method for the determination of the complex refractive index of size sizefractionated," Aerosol Science and Technology, vol. 34, pp. 535-549, 2001.

[38] Malvern, "Mastersizer 2000 application note. Determination of the particle absorption.," 2001.

[Online].

Available:

http://www.atomikateknik.com/en/pdfen/Determination\%20of\%20the\%20particle\%20abs orption\%20for\%20laser\%20diffraction\%20size\%20calculations.pdf. [Accessed 0109 2014].

[39] F. C. Ferraris, W. Guthrie, A. I. Aviles, M. Peltz, R. Haupt and S. B. MacDonald, "NIST Special Publication 260-166. Certification of SRM 114q: Part II (Particle size distribution).," NIST, Gaithersburgh, 2006.

[40] G. F. Coates and C. A. Hulse, "A comparison of four methods of size analysis of finegrained sediments," New Zealand Journal of Geology and, vol. 28, pp. 369-380, 1985.

[41] W. Kunkel, "Magnitude and Character of Errors Produced by Shape Factors in Stokes' Law Estimates of Particle Radius,” J. Appl. Phys., vol. 19, pp. 1056-1058, 1948.

[42] J. Le Roux, "Application of the Hofmann shape entropy to determine the settling velocity of irregular, semi-ellipsoidal grains," Sedimentary Geology, vol. 149, pp. 237-243, 2002.

[43] J. Oliver, G. Hicken and C. Orr, "Rapid, automatic particle-size analysis in the subsieve range," Powder Technology, no. 4, pp. 257-263, 1970. 
[44] J. Bullard and E. Garboczi, "Defining shape measures for 3-D star-shaped particles: sphericity, roundness, and dimensions," Powder Technology, no. 249, pp. 241-252, 2013.

[45] E. Garboczi and J. Bullard, "Contact function, uniform-thickness shell volume, and convexity measure for 3-D star-shaped particles," Powder Technology, no. 237, pp. 191$201,2013$.

[46] AnaTec, "FPA. Fine Particle Analyser," [Online]. Available: http://www.anatec.com/website/_images/produkte/fpa/FPA_English.pdf. [Accessed 11 2016].

[47] P. Pendleton and A. Badalyan, "Gad Adsorption Data Uncertainty and Propogation Analyses," Adsorption, vol. 11, no. 1, pp. 61-66, 2005.

[48] R. Pugh and L. Bergström, Surface and Colloidal Chemistry in Advanced Ceramics Processing, New York: Marcel Dekker, 1994.

[49] T. Papathansiou and D. Guell, Flow Induced Alignment in Composite Materials, Cambridge: Woodhead Publishing, 1997.

[50] H. Azari and E. Garboczi, "NCHRP Web-only document 156: Optical Sizing and Roundness Determination of Glass Beads Used in Traffic Markings," 2010. [Online]. Available: http://onlinepubs.trb.org/onlinepubs/nchrp/nchrp_w156.pdf. [Accessed 0409 2014].

[51] P. Gottlieb, G. Wilkie, D. Sutherland, E. Ho-Tun, S. P. K. Suthers, B. Jenkins, S. Spencer, A. Butcher and J. Rayner, "Using quantitative electron microscopy for process mineralogy applications," JOM, vol. 52, no. 4, pp. 24-25, 2000.

[52] A. Laskin and J. Cowin, "Automated Single-Particle SEM/EDX Analysis of Submicrometer Particles down to $0.1 \mu \mathrm{m}$," Anal. Chem., vol. 73, no. 5, pp. 1023-1029, 2001.

[53] D. Pirre, A. Butcher, M. Power, P. Gottlieb and G. Miller, "Rapid quantitative mineral and phase analysis using automated scanning electron microscopy (QemSCAN); potential applications in forensic geoscience," Geological Societym London, Special Publication, vol. 232, pp. 123-136, 2004.

[54] European Commitee for Standardization, "Tests for mechnical and physical properties of aggregates - Part 6: Determination of particle density and water absorption," CEN, Brussels, 2002. 
[55] G. Polya and G. Szego, "Isoperimetric Inequalities in Mathematical Physics," Princeton University Press, Princeton, 1951.

[56] C. Bohren and D. Huffman, Absorption and Scattering of Light by Small Particles, New York: John Wiley \& Sons, 1983. 

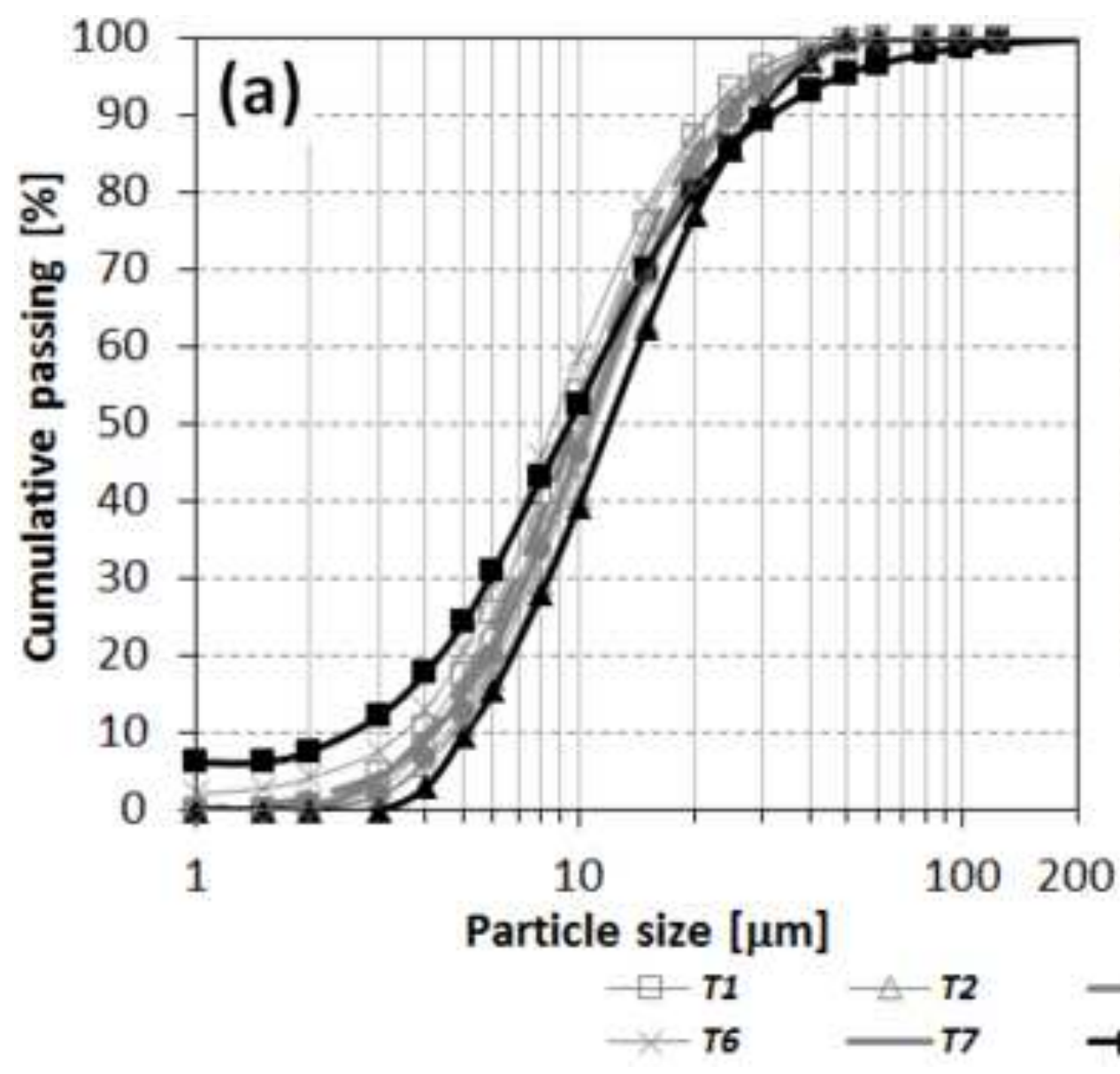

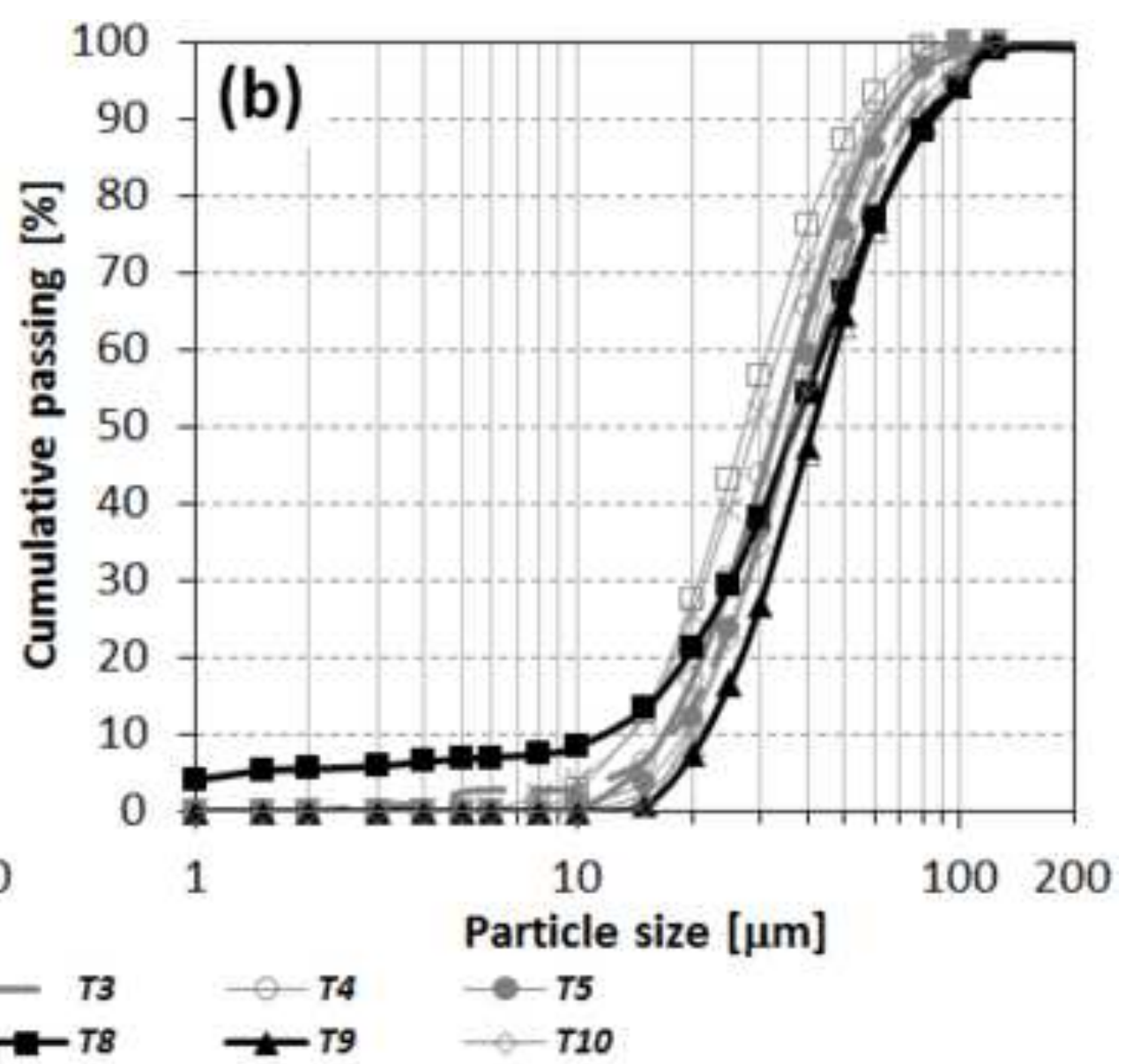




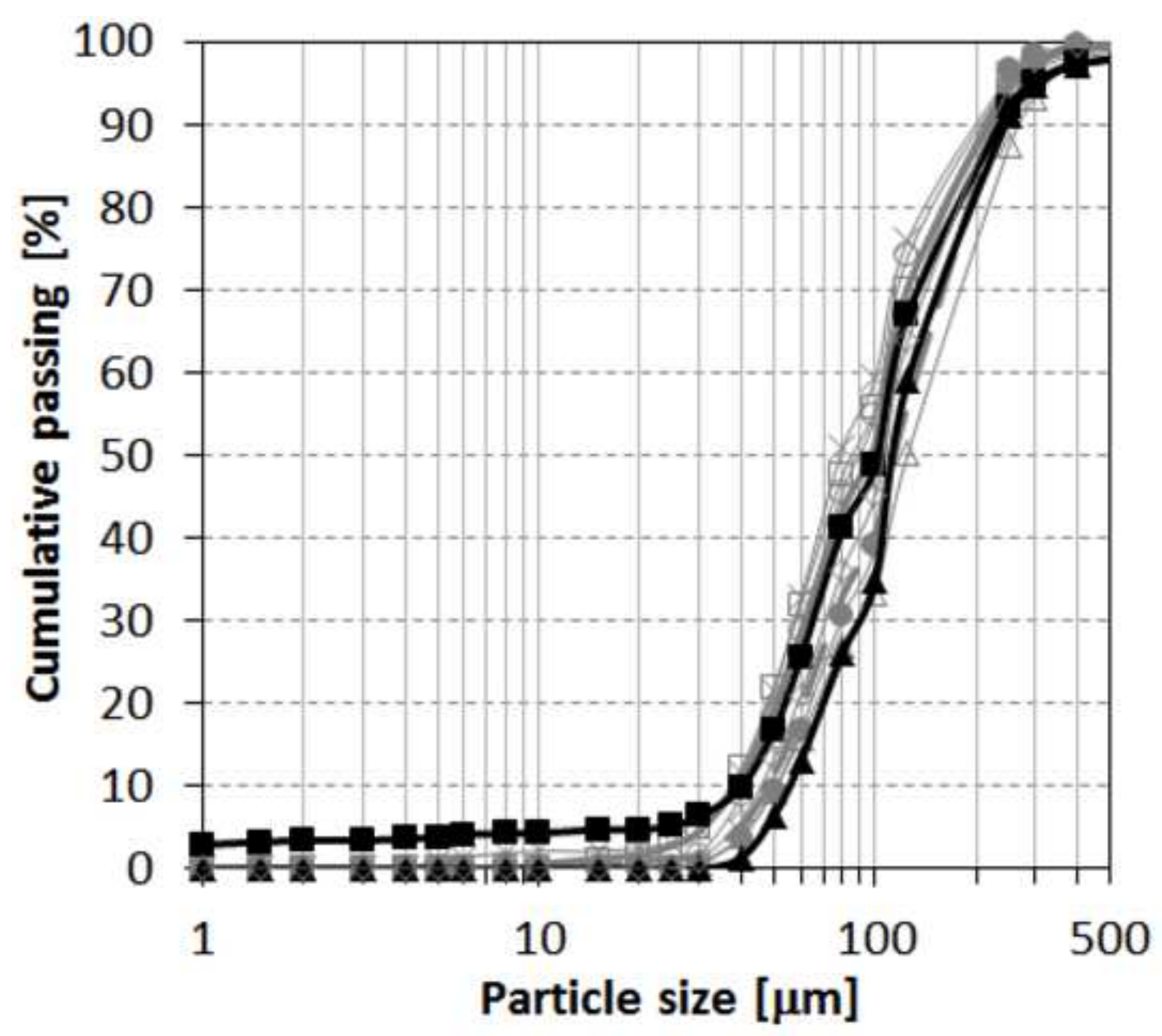

$\begin{array}{lllll}\square T 1 & -T 2 & -T 3 & -T 4 & -T 5 \\ \times T 6 & -T 7 & -T 8 & -T 9 & -T 10\end{array}$



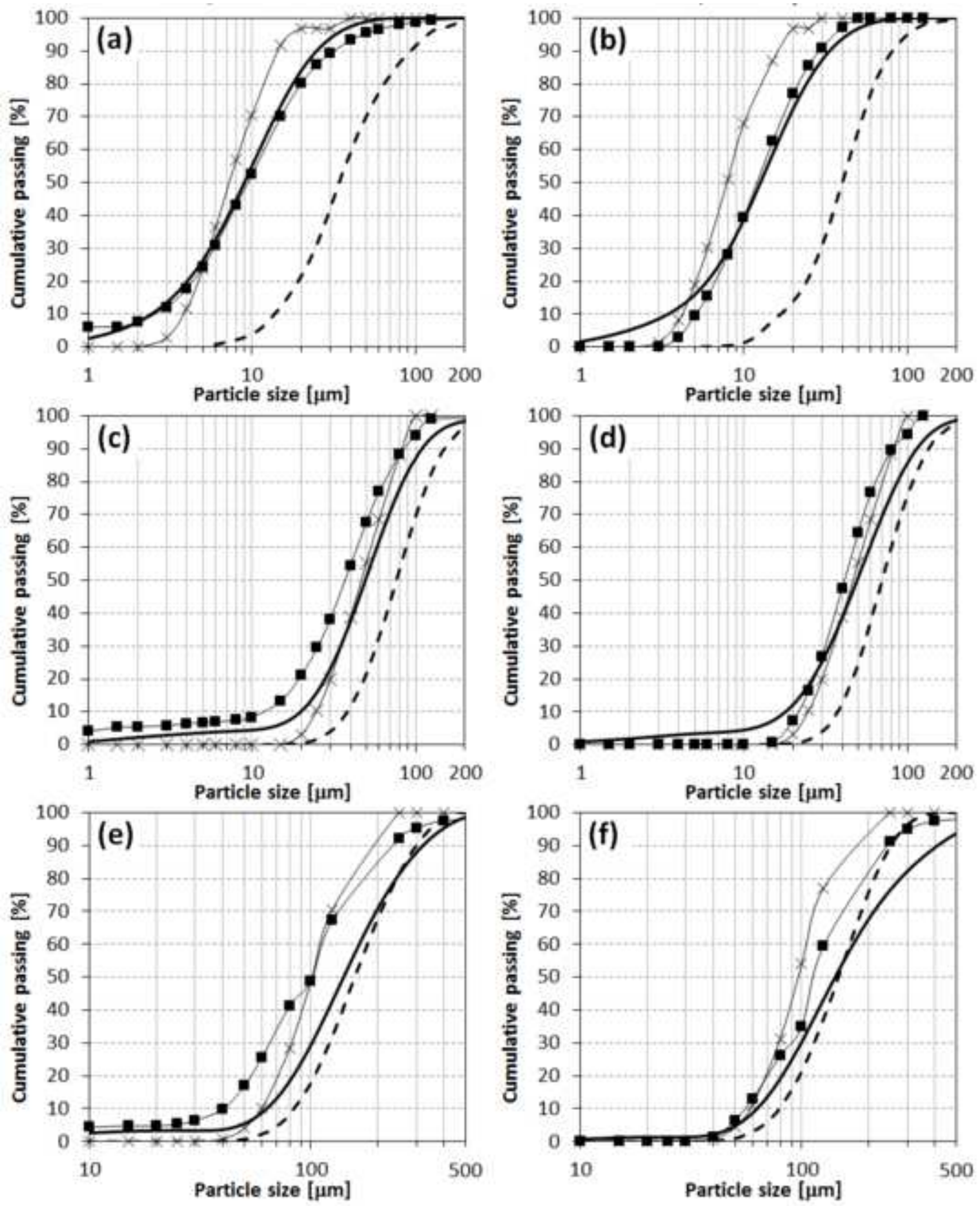

- -Sefígraph

L Loser Diffroction

-W- UCT + spherikel harmanics 


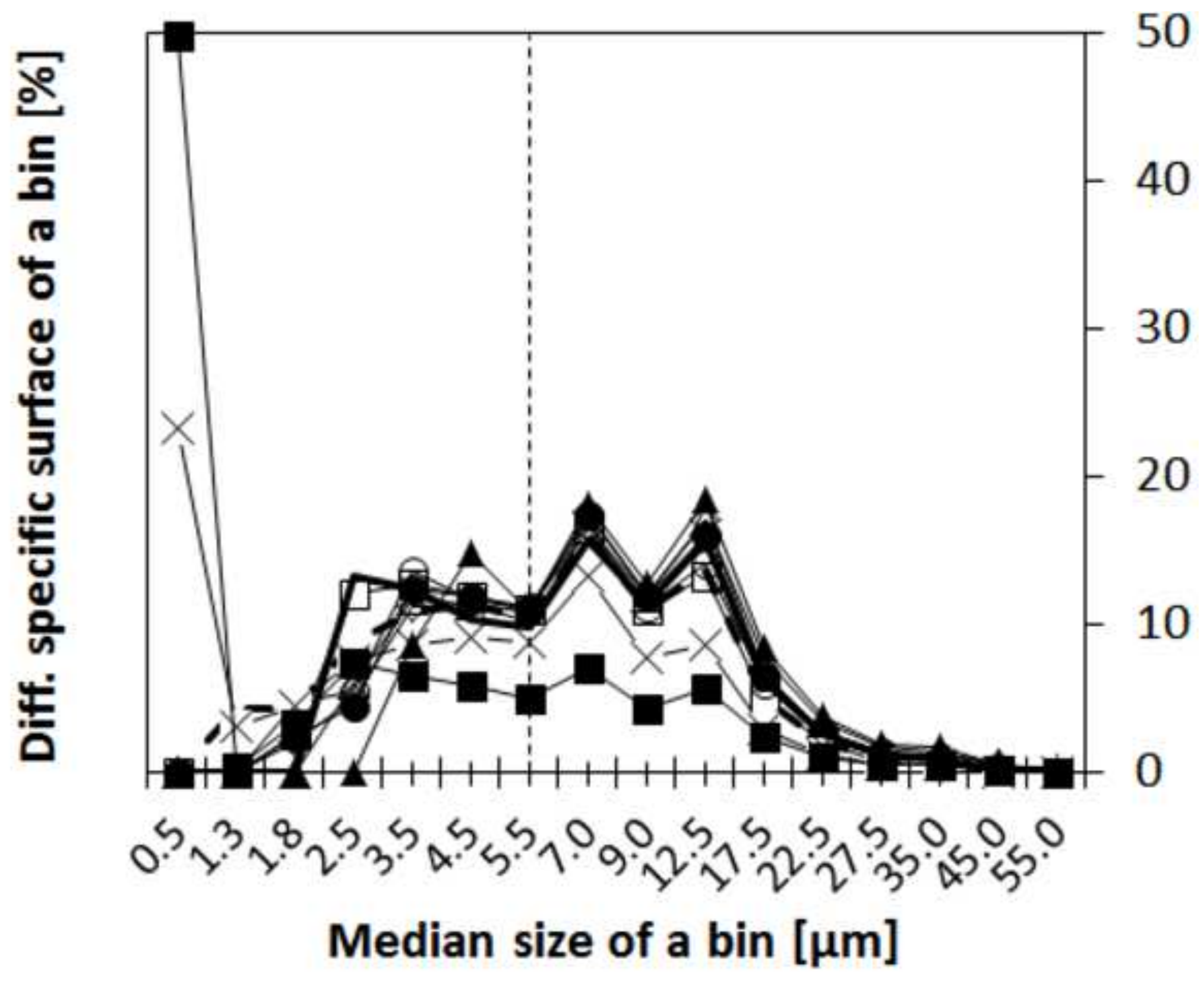
$-\square-T 1-1$
$\triangle T 2-1$
- - T3-1
- T T-1
$\rightarrow T 5-1 \quad-X-T 6-1$
$T 7-1$
- $-T 8-1$
$\longrightarrow$ T9-1
$\curvearrowright$ T10-1 


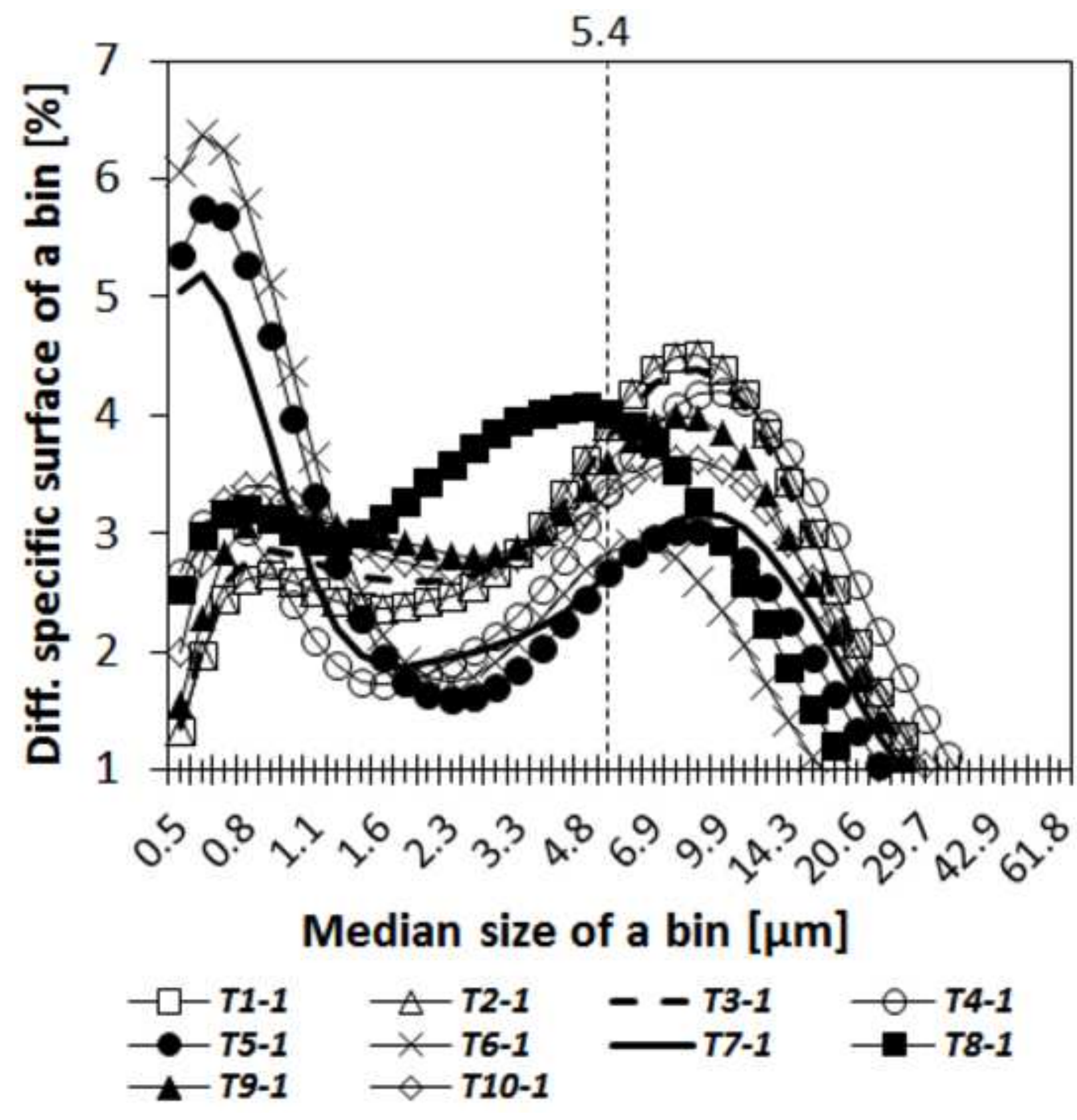



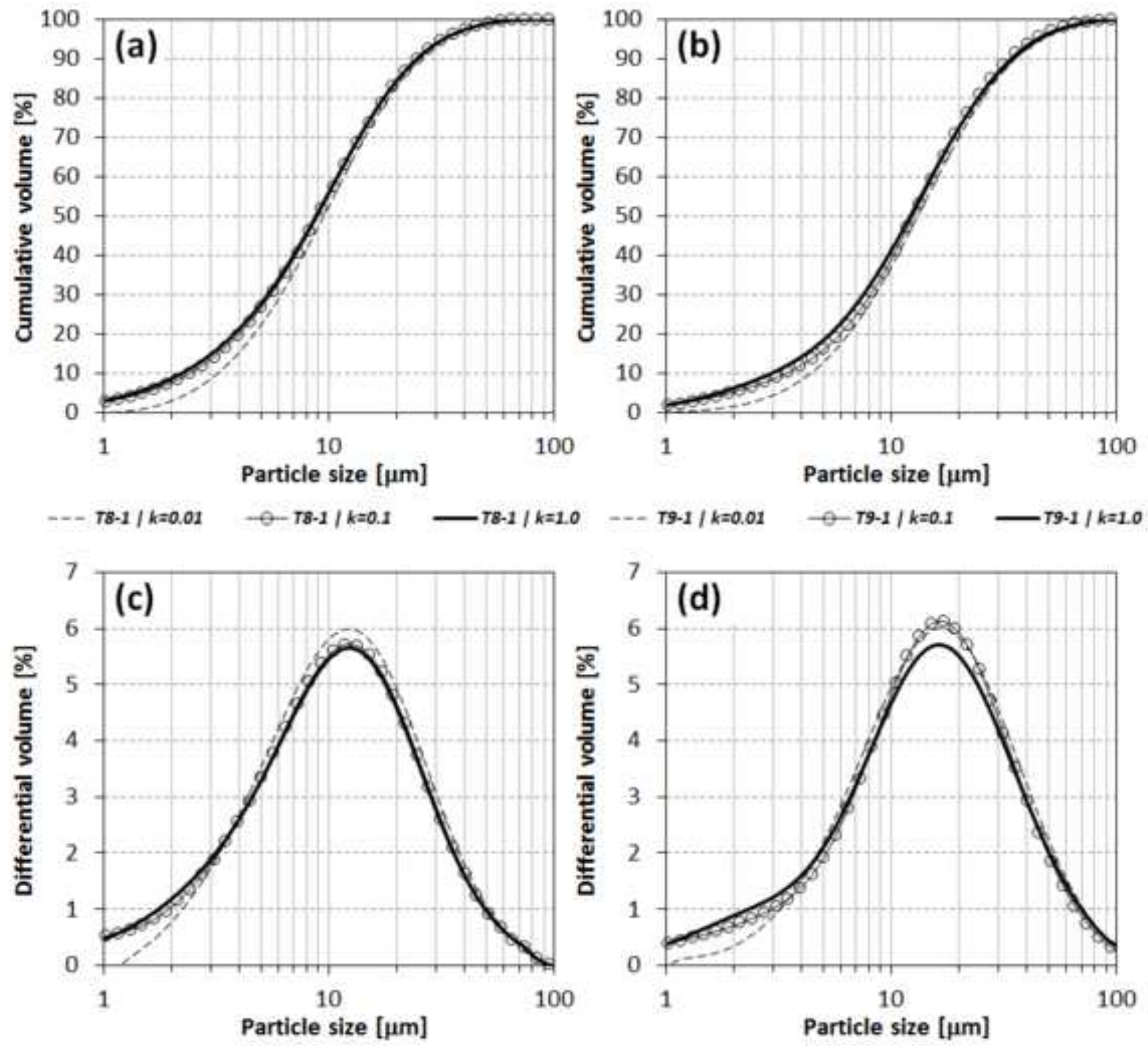


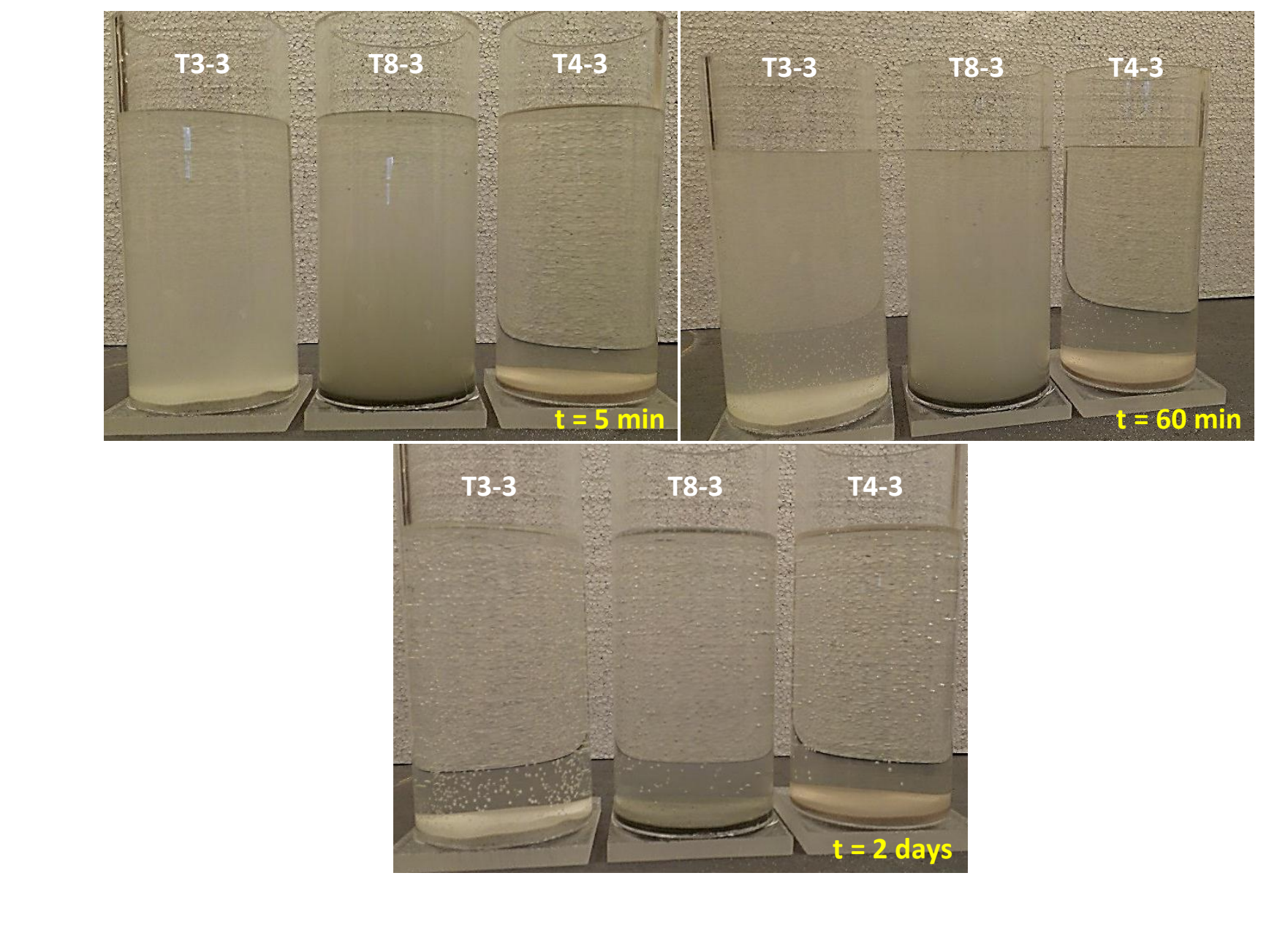

Figure 8 8
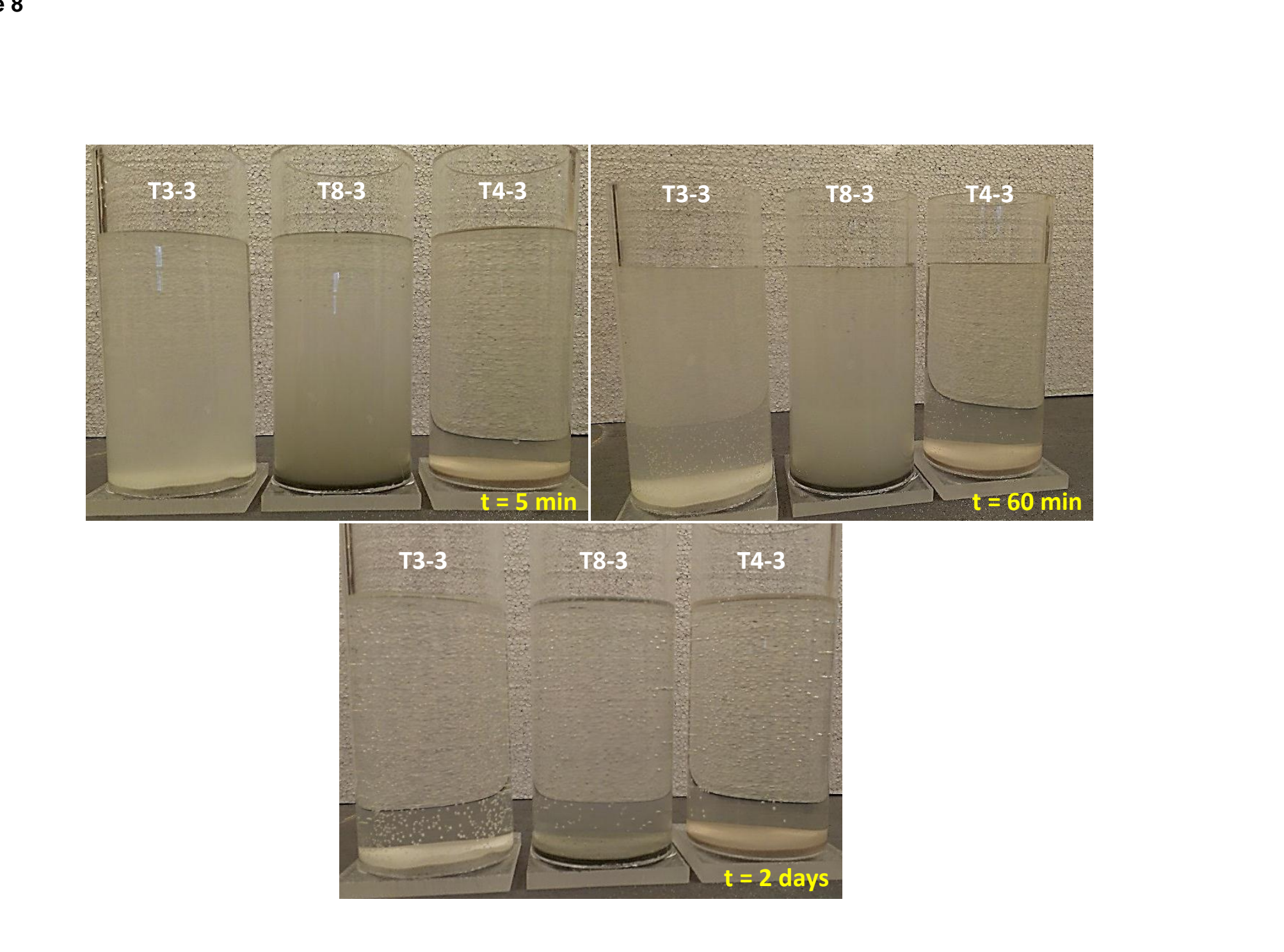


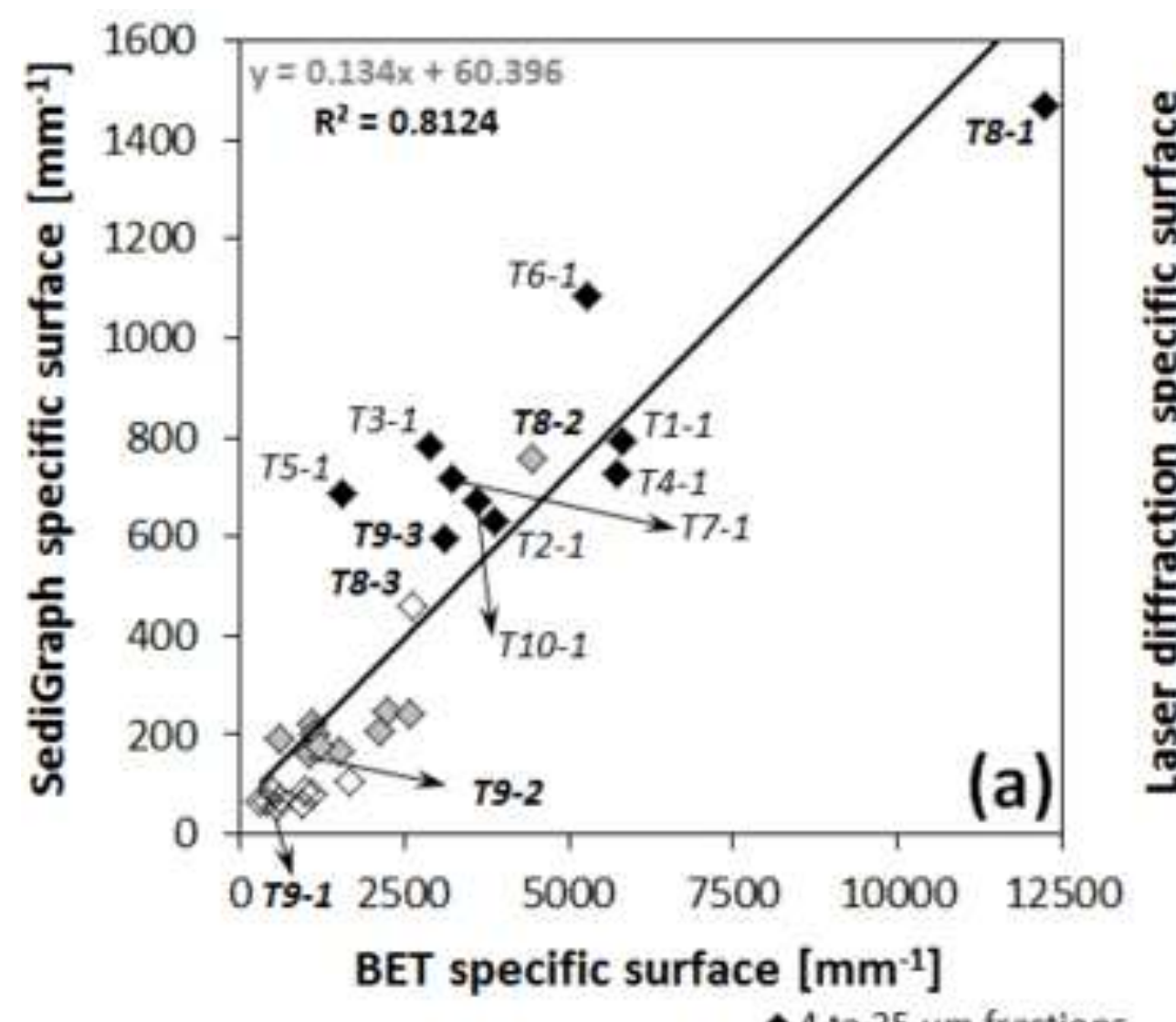

$\bullet 4$ to $25 \mu$ m fractions

$\diamond 40$ to $250 \mu \mathrm{m}$ fractions

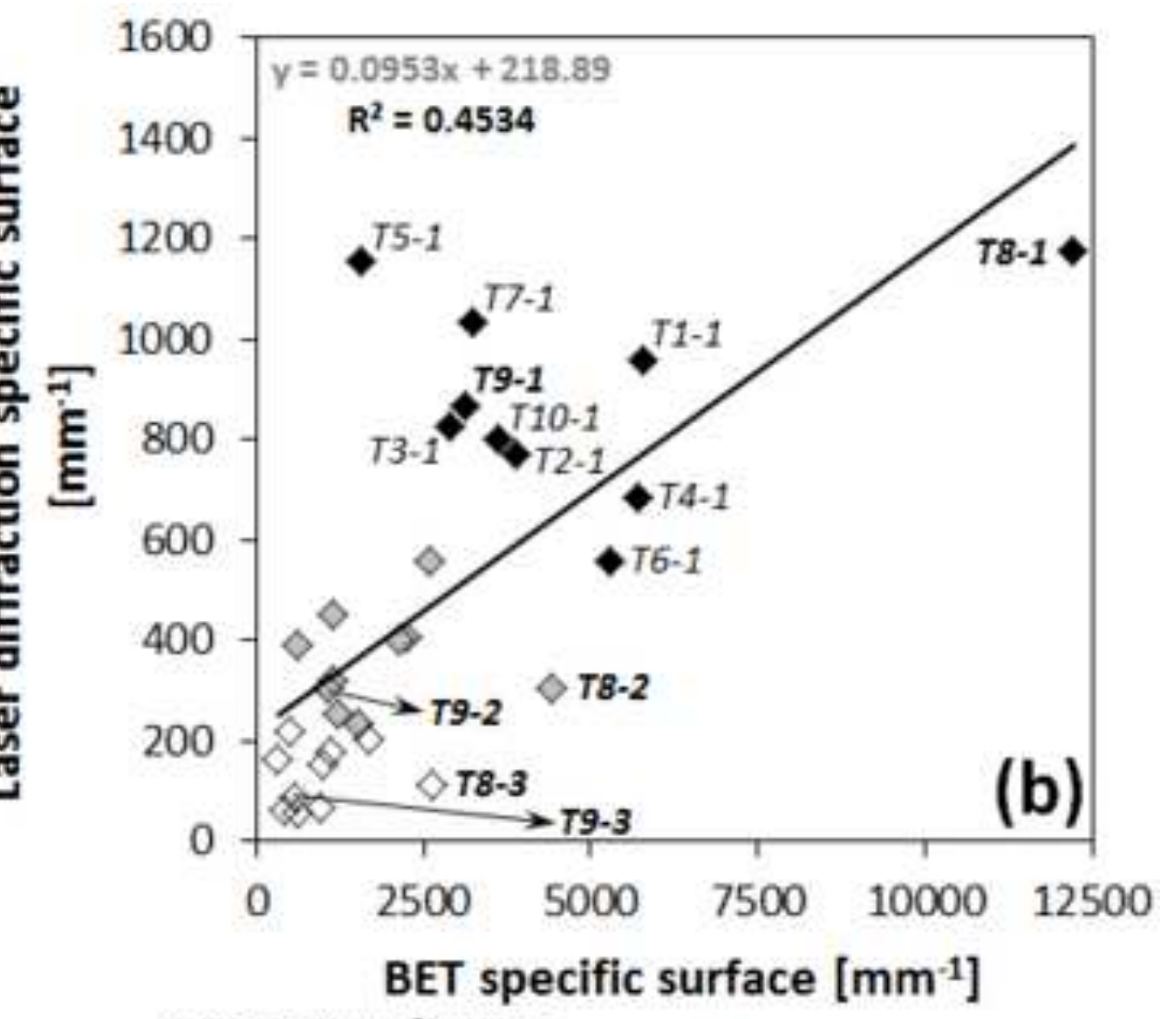

$\diamond 20$ to $60 \mu \mathrm{m}$ fractions 

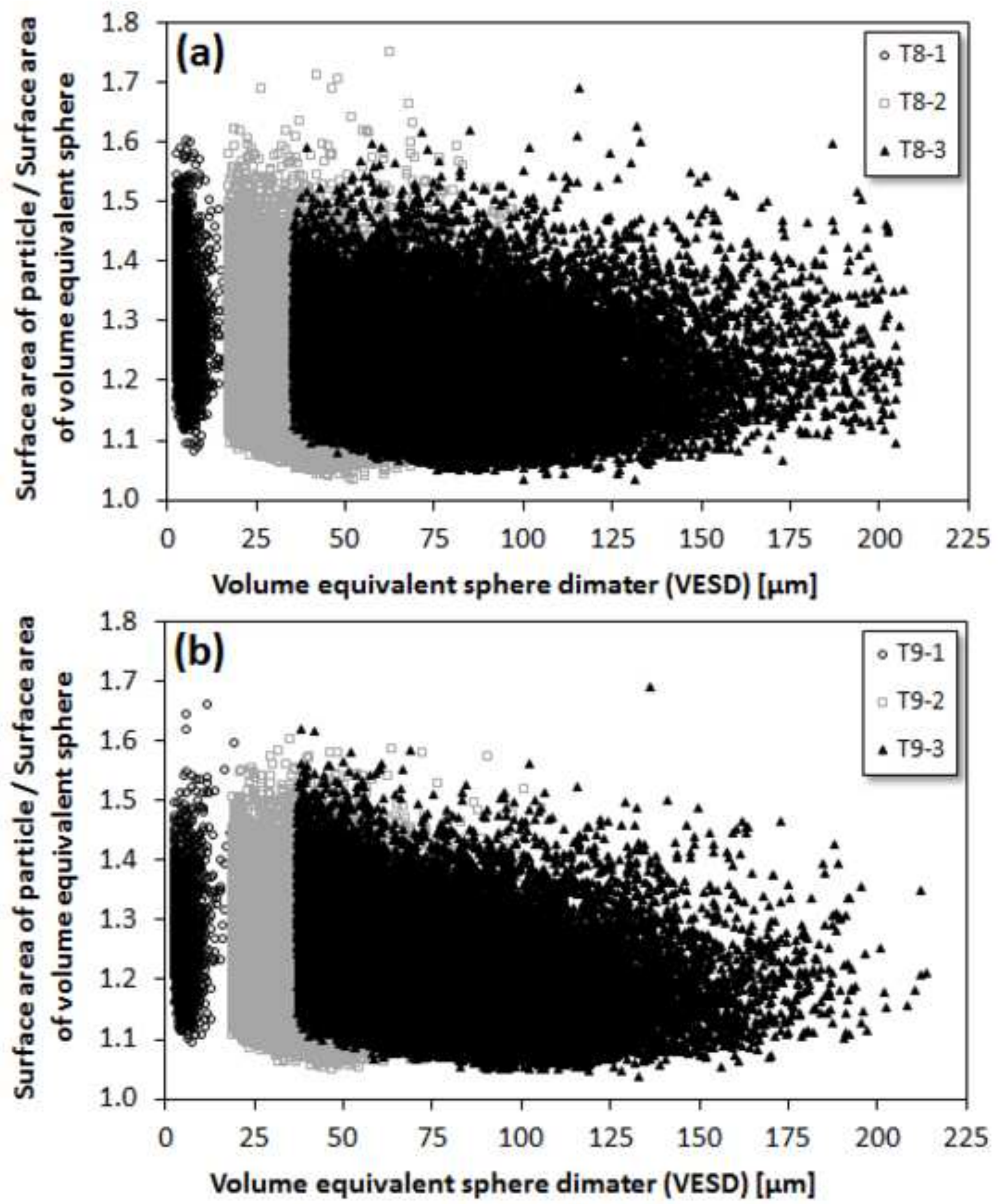


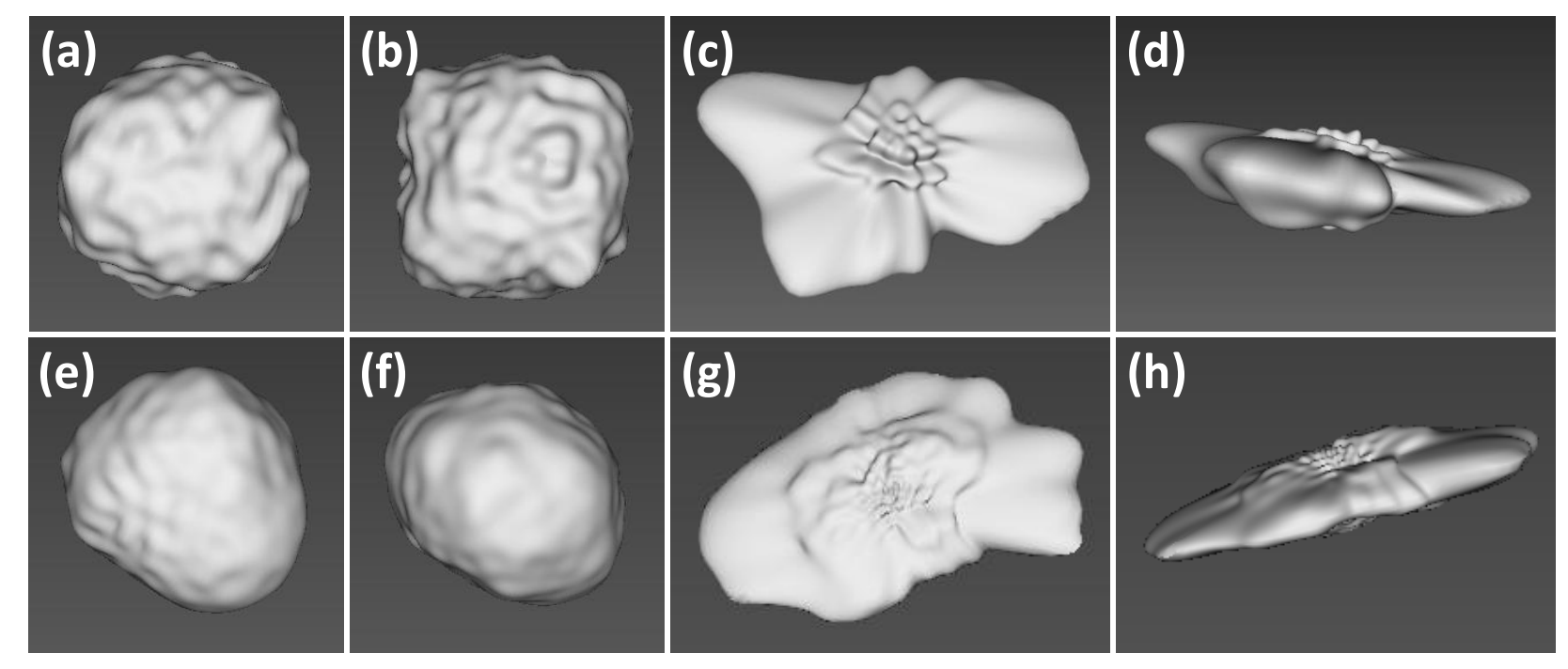

Figure 11 


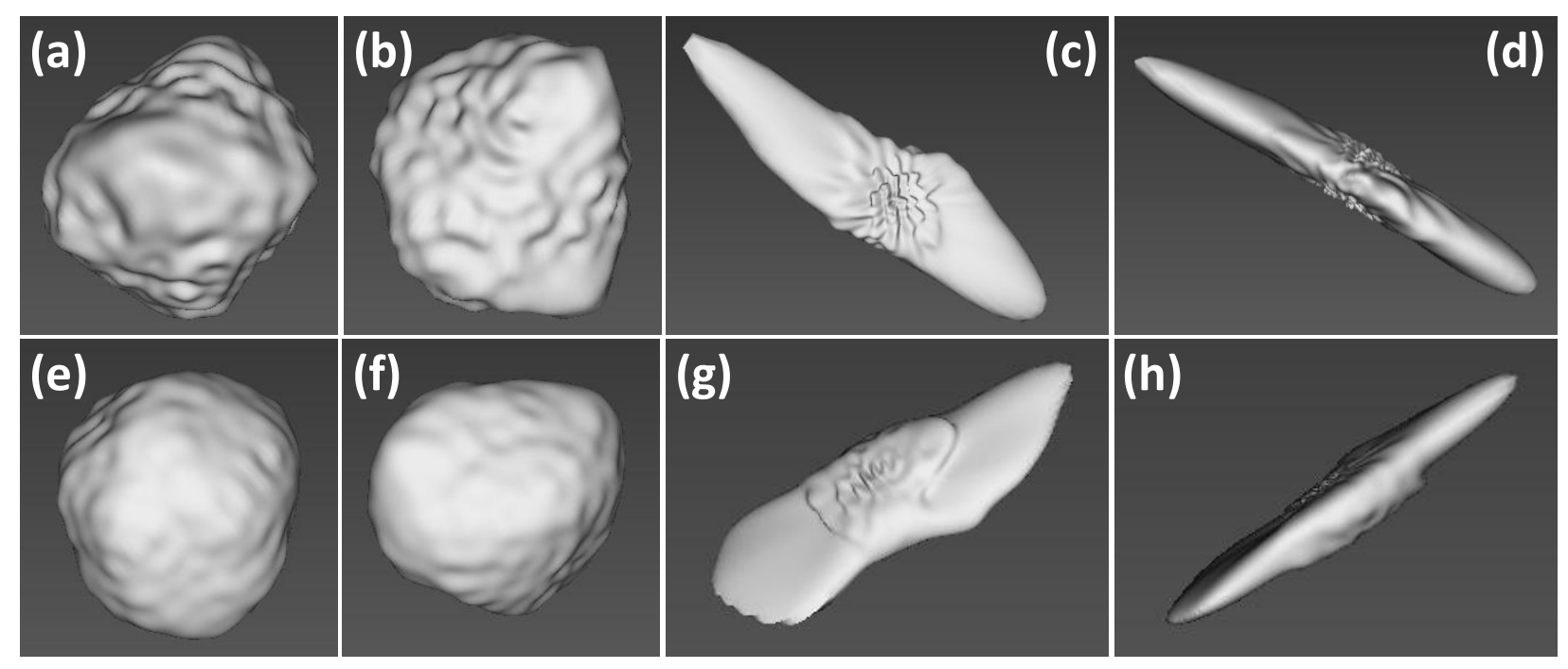


Table 1: Crushed rock fines used for the study.

\begin{tabular}{|c|c|c|c|c|c|c|c|c|c|c|c|}
\hline \multicolumn{2}{|c|}{ Rock type } & $\begin{array}{c}\text { Mylonitic } \\
\text { quartz } \\
\text { diorite }\end{array}$ & $\begin{array}{l}\text { Gneiss/ } \\
\text { granite }\end{array}$ & Quartzite & Anorthosite & Limestone & Limestone & Dolomite & Basalt & Aplite & $\begin{array}{c}\text { Granite/ } \\
\text { gneiss }\end{array}$ \\
\hline \multicolumn{2}{|c|}{$\begin{array}{c}\text { Rock type } \\
\text { designation }\end{array}$} & $\mathrm{T} 1$ & $\mathrm{~T} 2$ & $\mathrm{~T} 3$ & $\mathrm{~T} 4$ & $\mathrm{~T} 5$ & T6 & $\mathrm{T} 7$ & $\mathrm{~T} 8$ & T9 & $\mathrm{T} 10$ \\
\hline Fraction & $\begin{array}{c}\text { Nominal } \\
\text { size }^{\mathrm{a}}\end{array}$ & \multicolumn{10}{|c|}{ Designation of crushed aggregate fines } \\
\hline Fine & 4 to 25 & $\mathrm{~T} 1-1$ & $\mathrm{~T} 2-1$ & T3-1 & T4-1 & T5-1 & T6-1 & T7-1 & T8-1 & T9-1 & T10-1 \\
\hline Medium & 20 to 60 & $\mathrm{~T} 1-2$ & $\mathrm{~T} 2-2$ & T3-2 & T4-2 & T5-2 & T6-2 & T7-2 & $\mathrm{T} 8-2$ & T9-2 & $\mathrm{T} 10-2$ \\
\hline Coarse & 40 to 250 & $\mathrm{~T} 1-3$ & T2-3 & T3-3 & T4-3 & T5-3 & T6-3 & T7-3 & T8-3 & T9-3 & T10-3 \\
\hline
\end{tabular}

${ }^{a}$ The nominal size is approximate given in terms of the $\mathrm{d}_{10}$ and $\mathrm{d}_{90}$ diameters, which means that each size range can include up to about $10 \%$, by mass, smaller and larger particles. 
Table 2: Mineralogical composition of $4 \mu \mathrm{m}$ to $25 \mu \mathrm{m}$ powder fractions determined with quantitative XRD.

\begin{tabular}{|c|c|c|c|c|c|c|c|c|c|c|}
\hline Rock type & 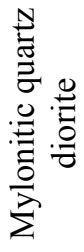 & 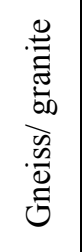 & 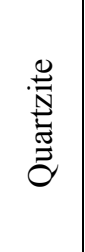 & 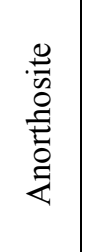 & $\begin{array}{l}\stackrel{0}{\Xi} \\
\stackrel{\Xi}{\mathscr{E}} \\
\stackrel{\Xi}{\Xi}\end{array}$ & $\begin{array}{l}\tilde{\Xi} \\
\tilde{0} \\
\stackrel{\Xi}{\Xi} \\
\Xi \\
\Xi\end{array}$ & $\begin{array}{l}\stackrel{0}{\stackrel{\Xi}{\Xi}} \\
\frac{0}{0} \\
0\end{array}$ & 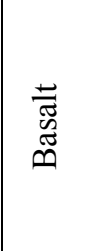 & $\stackrel{\frac{9}{7}}{\frac{2}{4}}$ & 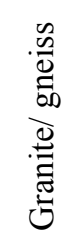 \\
\hline Rock type designation & T1 & $\mathrm{T} 2$ & T3 & $\mathrm{T} 4$ & T5 & T6 & T7 & T8 & T9 & $\mathrm{T} 10$ \\
\hline Tested fraction & \multicolumn{10}{|c|}{$4 \mu \mathrm{m}$ to $25 \mu \mathrm{m}$} \\
\hline $\begin{array}{l}\text { Mineral or group of } \\
\text { minerals }\end{array}$ & \multicolumn{10}{|c|}{ Mass \% } \\
\hline Quartz & 27.9 & 20.9 & 90.0 & 6.5 & 2.3 & 2.5 & 1.1 & 8.9 & 36.2 & 17.8 \\
\hline Carbonate minerals & 4.4 & - & 3.6 & 10.6 & 97.7 & 95.0 & 95.0 & 8.3 & - & 5.0 \\
\hline Epidote minerals & 8.4 & - & - & 24.4 & - & - & - & 7.6 & - & - \\
\hline Feldspar minerals & 37.7 & 63.9 & 3.9 & 33.1 & - & 0.4 & 0.6 & 26.5 & 58.2 & 58.8 \\
\hline Sheet silicates & 8.0 & 8.1 & 1.5 & 20.4 & - & 1.5 & 0.7 & 5.2 & 2.7 & 9.2 \\
\hline Chlorite & 11.3 & 1.4 & 1.0 & 2.6 & - & 0.6 & \begin{tabular}{|l|}
1.6 \\
\end{tabular} & 20.2 & 1.7 & 0.5 \\
\hline Inosilicate minerals & 1.0 & 3.9 & - & 2.3 & - & - & \begin{tabular}{|l|}
1.1 \\
\end{tabular} & 11.0 & 1.2 & 8.7 \\
\hline Iron oxide minerals & - & - & - & - & - & - & - & 3.5 & - & - \\
\hline Other minerals & 1.3 & 1.9 & - & 0.2 & - & - & - & 8.8 & - & - \\
\hline
\end{tabular}


Table 3: Real part of the complex refractive indices of the crushed aggregate fines used for the study [32], [34], [35].

\begin{tabular}{|c|c|c|c|c|c|c|c|c|}
\hline \multirow{2}{*}{$\begin{array}{l}\text { Mineral } \\
\text { group }\end{array}$} & \multirow{2}{*}{$\begin{array}{c}\text { Main }^{\mathrm{a}} \text { minerals } \\
\text { present in the } \\
\text { crushed rock } \\
\text { fines used for } \\
\text { the study }\end{array}$} & \multicolumn{7}{|c|}{ Real part (n) of the complex refractive index (m) } \\
\hline & & $\begin{array}{c}\text { Along } \\
\text { indicatrix } \\
\mathrm{x} \text {-axis } \\
\left(\mathrm{n}_{\alpha=\mathrm{x}}\right) \\
\end{array}$ & $\begin{array}{c}\text { Along } \\
\text { indicatrix } \\
y \text {-axis } \\
\left(\mathrm{n}_{\beta=\mathrm{y}}\right) \\
\end{array}$ & $\begin{array}{c}\text { Along } \\
\text { indicatrix z- } \\
\text { axis } \\
\left(\mathrm{n}_{\gamma=\mathrm{z}}\right)\end{array}$ & $\begin{array}{l}\text { Weighted } \\
\text { average } \\
\text { (WAV) }\end{array}$ & \multicolumn{3}{|c|}{ Average } \\
\hline \multicolumn{2}{|c|}{ Quartz } & 1.544 & 1.553 & - & 1.547 & \multirow{9}{*}{1.56} & \multirow{9}{*}{-} & \multirow{12}{*}{1.60} \\
\hline \multirow{2}{*}{$\begin{array}{c}\text { Carbonate } \\
\text { minerals }\end{array}$} & Calcite & 1.486 & 1.658 & - & 1.543 & & & \\
\hline & Dolomite & 1.500 & 1.679 & - & 1.560 & & & \\
\hline \multirow{4}{*}{$\begin{array}{l}\text { Feldspar } \\
\text { minerals }\end{array}$} & $\begin{array}{l}\text { Plagioclase } \\
\text { (albite) }\end{array}$ & 1.527 & 1.531 & 1.538 & 1.532 & & & \\
\hline & Oligoclase & 1.539 & 1.543 & 1.547 & 1.543 & & & \\
\hline & Labradorite & 1.554 & 1.559 & 1.562 & 1.558 & & & \\
\hline & Microcline & 1.514 & 1.518 & 1.521 & 1.518 & & & \\
\hline \multirow{2}{*}{$\begin{array}{c}\text { Sheet silicate } \\
\text { minerals }\end{array}$} & Chlorite & 1.610 & 1.620 & 1.620 & 1.617 & & & \\
\hline & Paragonite & 1.572 & 1.602 & 1.605 & 1.593 & & & \\
\hline \multirow{3}{*}{$\begin{array}{l}\text { Epidote } \\
\text { minerals }\end{array}$} & Epidote & 1.733 & 1.755 & 1.765 & 1.751 & \multirow{3}{*}{-} & \multirow{3}{*}{1.72} & \\
\hline & Zoisite & 1.695 & 1.699 & 1.711 & 1.702 & & & \\
\hline & Clinozoisite & 1.693 & 1.700 & 1.712 & 1.702 & & & \\
\hline
\end{tabular}

${ }^{\mathrm{a}}$ Minerals present in mass fractions exceeding 0.09 according to the XRD analysis. 
Table 4: Densities of the analyzed crushed aggregate fines as measured by helium pycnometry.

\begin{tabular}{|c|c|c|c|c|c|c|c|c|c|c|c|}
\hline \multicolumn{2}{|c|}{ Rock type } & $\begin{array}{c}\text { Mylonitic } \\
\text { quartz } \\
\text { diorite }\end{array}$ & $\begin{array}{l}\text { Gneiss/ } \\
\text { granite }\end{array}$ & Quartzite & Anorthosite & Limestone & Limestone & Dolomite & Basalt & Aplite & $\begin{array}{c}\text { Granite/ } \\
\text { gneiss }\end{array}$ \\
\hline \multicolumn{2}{|c|}{$\begin{array}{l}\text { Rock type } \\
\text { designation }\end{array}$} & $\mathrm{T} 1$ & $\mathrm{~T} 2$ & $\mathrm{~T} 3$ & $\mathrm{~T} 4$ & $\mathrm{~T} 5$ & T6 & $\mathrm{T} 7$ & $\mathrm{~T} 8$ & T9 & $\mathrm{T} 10$ \\
\hline \multirow[t]{2}{*}{ Fraction } & $\begin{array}{l}\text { Nominal } \\
\text { size }\end{array}$ & \multicolumn{10}{|c|}{ Density } \\
\hline & {$[\mu \mathrm{m}]$} & \multicolumn{10}{|c|}{$\left[\mathrm{kg} / \mathrm{m}^{3}\right]$} \\
\hline Fine & 4 to 25 & 2.78 & 2.72 & 2.67 & 2.88 & 2.72 & 2.74 & 2.85 & 2.91 & 2.66 & 2.73 \\
\hline Medium & 20 to 60 & 2.77 & 2.71 & 2.67 & 2.94 & 2.72 & 2.76 & 2.85 & 2.94 & 2.65 & 2.75 \\
\hline Coarse & 40 to 250 & 2.77 & 2.70 & 2.66 & 2.98 & 2.72 & 2.77 & 2.85 & 2.94 & 2.64 & 2.74 \\
\hline
\end{tabular}


Table 5: $\mu \mathrm{CT}$ and spherical harmonic analysis - image size, pixel size and number of analysed particles.

\begin{tabular}{l|c|c|c}
\hline Fraction & $\begin{array}{c}\mathbf{4} \boldsymbol{\mu m} \text { to } 25 \\
\boldsymbol{\mu m}\end{array}$ & $\begin{array}{c}\mathbf{2 0} \boldsymbol{\mu \mathbf { m }} \text { to } 60 \\
\boldsymbol{\mu m}\end{array}$ & $\begin{array}{c}\mathbf{4 0} \boldsymbol{\mu m} \text { to } 250 \\
\boldsymbol{\mu m}\end{array}$ \\
\hline $\begin{array}{l}\text { Average pixel size used for } \\
\text { the } \boldsymbol{\mu C T} \text { scanning }[\boldsymbol{\mu m}]\end{array}$ & 0.32 & 1.71 & 3.87 \\
\hline $\begin{array}{l}\text { Image size [px] } \\
\begin{array}{l}\text { Average number of } \\
\text { particles analysed }\end{array}\end{array}$ & ca. $900 \times 968$ & $2000 \times 2000$ & $2000 \times 2000$ \\
\hline
\end{tabular}


Table 6: Smallest detectable particle sizes and measured characteristic properties of the particles.

\begin{tabular}{|c|c|c|c|c|c|c|}
\hline \multirow{3}{*}{$\begin{array}{l}\text { Measurement } \\
\text { method }\end{array}$} & $\begin{array}{c}4 \mu \mathrm{m} \text { to } \\
25 \mu \mathrm{m}\end{array}$ & $\begin{array}{c}20 \mu \mathrm{m} \text { to } \\
60 \mu \mathrm{m}\end{array}$ & $\begin{array}{c}40 \mu \mathrm{m} \text { to } \\
250 \mu \mathrm{m}\end{array}$ & \multirow{3}{*}{$\begin{array}{c}\text { Particle } \\
\text { dispersion } \\
\text { mechanism }\end{array}$} & \multirow{3}{*}{$\begin{array}{l}\text { Reported size } \\
\text { parameter }\end{array}$} & \multirow{3}{*}{$\begin{array}{l}\text { Measured characteristic } \\
\text { property of a particle }\end{array}$} \\
\hline & \multicolumn{3}{|c|}{$\begin{array}{c}\text { Expected smallest detectable } \\
\text { particle size }\end{array}$} & & & \\
\hline & \multicolumn{3}{|c|}{$[\mu \mathrm{m}]$} & & & \\
\hline $\mathbf{X S}$ & $0.1^{\mathrm{a}}$ & $0.1^{\mathrm{a}}$ & $0.1^{\mathrm{a}}$ & $\begin{array}{c}\text { Particles } \leq \\
\mathbf{1 0 0} \boldsymbol{\mu m :} \\
\text { dispersed in } \\
\text { liquid by } \\
\text { circulation } \\
\text { pump }\end{array}$ & $\begin{array}{c}\text { Mass } \\
\text { equivalent } \\
\text { spherical } \\
\text { diameter }\end{array}$ & $\begin{array}{l}\text { Particles }>\mathbf{1 0 0} \boldsymbol{\mu m} \text { : size } \\
\text { of a square hole through } \\
\text { which they will pass; } \\
\text { Particles } \leq \mathbf{1 0 0} \boldsymbol{\mu m} \text { : } \\
\text { settling velocity }\end{array}$ \\
\hline LD & $0.02^{\mathrm{a}}$ & $0.02^{\mathrm{a}}$ & $0.02^{\mathrm{a}}$ & $\begin{array}{l}\text { Dispersed in } \\
\text { IPA by } \\
\text { circulation } \\
\text { pump and } \\
\text { ultrasonic } \\
\text { treatment }\end{array}$ & $\begin{array}{l}\text { Volume } \\
\text { equivalent } \\
\text { spherical } \\
\text { diameter }\end{array}$ & $\begin{array}{l}\text { Angular distribution of the } \\
\text { intensity of coherent light } \\
\text { forward-scattered by the } \\
\text { particle }\end{array}$ \\
\hline DIA & $4.29^{b}$ & $4.29^{b}$ & $4.29^{\mathrm{b}}$ & $\begin{array}{l}\text { Dispersed by } \\
\text { compressed } \\
\text { air at } 200 \mathrm{kPa} \\
\text { pressure }\end{array}$ & $\begin{array}{l}\text { Equivalent } \\
\text { area circle } \\
\text { diameter }\end{array}$ & $\begin{array}{l}\text { Area of a random 2-D } \\
\text { projection }\end{array}$ \\
\hline $\begin{array}{l}\mu \mathrm{CT}+ \\
\text { spherical } \\
\text { harmonics }\end{array}$ & $3.18^{\mathrm{c}}$ & $16.97^{\mathrm{c}}$ & $38.41^{\mathrm{c}}$ & $\begin{array}{l}\text { Dispersed in } \\
\text { epoxy resin } \\
\text { by vigorous } \\
\text { manual } \\
\text { agitation }\end{array}$ & $\begin{array}{l}\text { Volume } \\
\text { equivalent } \\
\text { spherical } \\
\text { diameter }\end{array}$ & Actual physical volume \\
\hline
\end{tabular}

${ }^{a}$ According to the specification from the vendor.

${ }^{b}$ Based on the pixel size of the obtained high-speed camera images, i.e. the projections of the smallest captured particles are only one pixel big.

${ }^{c}$ Dependant on the pixel size used for the $\mu \mathrm{CT}$ scanning. Only particles bigger than $8 \times 8 \times 8=512$ voxels have been included in the PSD analysis. 
Table 7: Sensitivity of the calculated specific surface values on the chosen imaginary component ( $\mathrm{k}$ ) of the complex refractive index (m).

\begin{tabular}{c|c|c|c}
\hline \multirow{2}{*}{$\begin{array}{c}\text { Type of } \\
\text { fines }\end{array}$} & \multicolumn{3}{|c}{ Calculated specific surface area $^{\mathrm{a}}$} \\
\cline { 2 - 4 } & $\mathrm{k}=0.01$ & $\mathrm{k}=0.1$ & $\mathrm{k}=1.0$ \\
\hline $\mathrm{T} 8-1$ & 882.9 & 1174.0 & 1279.5 \\
\hline $\mathrm{T} 9-1$ & 663.3 & 865.1 & 942.9 \\
\hline
\end{tabular}

${ }^{a}$ Assuming spherical particle shape. 
Table 8: Water absorption values of $0.063 \mathrm{~mm}$ to $2 \mathrm{~mm}$ fractions of the rocks used for obtaining the crushed filler samples.

\begin{tabular}{c|c|c|c|c|c|c|c|c|c|c}
\hline Rock type & $\begin{array}{c}\text { Mylonitic } \\
\text { quartz } \\
\text { diorite }\end{array}$ & $\begin{array}{c}\text { Gneiss/ } \\
\text { granite }\end{array}$ & Quartzite & Anorthosite & Limestone & Limestone & Dolomite & Basalt & Aplite & $\begin{array}{c}\text { Granite/ } \\
\text { gneiss }\end{array}$ \\
\hline $\begin{array}{c}\text { Rock type } \\
\text { designation }\end{array}$ & $\mathrm{T} 1$ & $\mathrm{~T} 2$ & $\mathrm{~T} 3$ & $\mathrm{~T} 4$ & $\mathrm{~T} 5$ & $\mathrm{~T} 6$ & $\mathrm{~T} 7$ & $\mathrm{~T} 8$ & $\mathrm{~T} 9$ & $\mathrm{~T} 10$ \\
\hline $\begin{array}{c}\text { Water } \\
\text { absorption }\end{array}$ & 0.4 & 0.4 & 0.2 & 0.7 & 0.2 & 0.6 & 0.2 & 0.9 & 0.7 & 0.3 \\
\hline
\end{tabular}

${ }^{a}$ Determined according to EN 1097-6 [54]. 
Table 9: Average ratio of actual surface area of particles as determined by $\mu \mathrm{CT}$ and spherical harmonics and specific surface area of volume equivalent sphere.

\begin{tabular}{|c|c|c|c|c|c|}
\hline \multicolumn{2}{|c|}{$4 / 25 \mu \mathrm{m}$ fractions } & \multicolumn{2}{c|}{$20 / 60 \mu \mathrm{m}$ fractions } & \multicolumn{2}{c|}{$40 / 250 \mu \mathrm{m}$ fractions } \\
\hline Designation & $\begin{array}{c}\text { Average of } \\
\mathrm{SA}^{\mathrm{a}} / \text { VESD } \\
\mathrm{SA}^{\mathrm{b}}\end{array}$ & Designation & $\begin{array}{c}\text { Average of } \\
\mathrm{SA}^{\mathrm{a}} / \text { VESD } \\
\mathrm{SA}^{\mathrm{b}}\end{array}$ & Designation & $\begin{array}{c}\text { Average of } \\
\mathrm{SA}^{\mathrm{a}} / \text { VESD } \\
\mathrm{SA}^{\mathrm{b}}\end{array}$ \\
\hline $\mathrm{T} 1-1$ & 1.30 & $\mathrm{~T} 1-2$ & 1.22 & $\mathrm{~T} 1-3$ & 1.20 \\
\hline $\mathrm{T} 2-1$ & 1.28 & $\mathrm{~T} 2-2$ & 1.23 & $\mathrm{~T} 2-3$ & 1.21 \\
\hline $\mathrm{T} 3-1$ & 1.28 & $\mathrm{~T} 3-2$ & 1.23 & $\mathrm{~T} 3-3$ & 1.23 \\
\hline $\mathrm{T} 4-1$ & 1.27 & $\mathrm{~T} 4-2$ & 1.21 & $\mathrm{~T} 4-3$ & 1.20 \\
\hline $\mathrm{T} 5-1$ & 1.25 & $\mathrm{~T} 5-2$ & 1.19 & $\mathrm{~T} 5-3$ & 1.19 \\
\hline $\mathrm{T} 6-1$ & 1.25 & $\mathrm{~T} 6-2$ & 1.19 & $\mathrm{~T} 6-3$ & 1.21 \\
\hline $\mathrm{T} 7-1$ & 1.27 & $\mathrm{~T} 7-2$ & 1.21 & $\mathrm{~T} 7-3$ & 1.23 \\
\hline $\mathrm{T} 8-1$ & 1.29 & $\mathrm{~T} 8-2$ & 1.20 & $\mathrm{~T} 8-3$ & 1.20 \\
\hline T9-1 & 1.26 & $\mathrm{~T} 9-2$ & 1.22 & T9-3 & 1.20 \\
\hline T10-1 & 1.26 & T10-2 & 1.23 & T10-3 & 1.21 \\
\hline AVERAGE & $\mathbf{1 . 2 7}$ & AVERAGE & $\mathbf{1 . 2 1}$ & AVERAGE & $\mathbf{1 . 2 1}$ \\
\hline
\end{tabular}

${ }^{a}$ Surface area of particle.

${ }^{\mathrm{b}}$ Surface area of volume equivalent sphere. 